\title{
AN ANALYSIS OF FACTORS AFFECTING CROSS DOCKING OPERATIONS
}

by

\author{
Kum Khiong Yang \\ Singapore Management University \\ Jaydeep Balakrishnan \\ University of Calgary, Canada
}

and

\author{
Chun Hung Cheng \\ The Chinese University of Hong Kong
}

\begin{abstract}
Acknowledgement
This work was partially funded by the Wharton-SMU Research Centre, Singapore Management University (Project No. 06-C207-SMU-017) and by the Research Grants Council of the Hong Kong Special Administrative Region, China (Project No. 41 1205).
\end{abstract}

\section{INTRODUCTION}

In today's logistical environment where small orders and frequent deliveries are expected, cross docking offers an important advantage. Cross docking is a logistical activity that consolidates shipments from inbound trailers to outbound trailers in buildings known as cross docks. At each cross dock, each inbound trailer typically arrives from a different origin, carrying shipments meant for different destinations. These shipments are then quickly unloaded from the inbound trailers, sorted, consolidated, and reloaded onto outbound trailers bound for different destinations. Typically, all shipment handling is completed within a day, with little or no holding of stock in the cross dock.

Cross docking offers a significant cost advantage. Instead of shipping small orders directly as less-than-truckload (LTL) shipments between origins and destinations, cross docking consolidates small orders into truck-load (TL) shipments. With cross docking, more frequent and economical deliveries are now viable as inbound and outbound trailers are now more fully loaded per trip. With frequent shipments, lesser inventory is also needed at the origins and destinations to avoid stock-outs. Many companies, such as Walmart and Harp's Food Stores, reported significant savings in transportation, inventory, and stock-out costs after implementing cross docking in their systems (Snyder 1995). Kinnear (1997) also reported similar improvement after implementing cross docking at Goodyear in Great Britain.

Naturally, like all systems, cross docking is no panacea. Jönsson and Silver (1987), for example, showed that in certain situations, retaining some inventory in a warehouse for a second shipment can produce a lower total cost. Waller, Cassady, and Ozment (2006) also showed that in certain situations, cross docking may require more total inventory than stocking inventory in a warehouse. While past literature has shown that cross docking is no panacea, its success, when it is used appropriately, depends very much on how well the system is designed and managed. For example, its success depends on how well the system of cross docks is located to connect the origins and destinations together. Sung and Song (2003), for example, proposed a Tabu-Search algorithm to determine the locations of cross docks and allocation of vehicles. Relaxing the assumption of shipping all demands through cross docks, Gumus and Bookbinder (2004) also proposed a procedure to determine the locations of cross docks and allocation of vehicles. Their objective is to design an efficient network of cross docks to minimize the total cost of 
transportation, inventory and facilities, allowing both direct and indirect shipments between the origins and destinations.

While designing an efficient network of cross docks is important, the success of cross-docking also depends on how well each individual cross dock is designed and managed. A poorly designed and managed cross dock will obviously increase the cost of handling shipments in the cross dock and negate the benefit of cross docking. To improve performance, a manager faces various options or decisions. For example, they can choose to transfer shipments either directly or indirectly between the trailers in the cross dock. They can use a different layout or choose to use fewer or more forklifts to handle the shipments. To unload the inbound trailers, they can open fewer or more receiving doors. A review of the past literature shows that no study has systematically examined the impact of these decisions on the operations of a cross dock. This provides a gap in the literature-which we propose to bridge by using computer simulation to study the impact of these decisions on the operational effectiveness of a cross dock. The advantage of using computer simulation is that it can realistically replicate the activities and congestion in a cross dock, and provide accurate insights on making the right decisions to improve performance. As an initial study of cross docks using computer simulation, this research will examine only a specific class of cross docks that provide a free staging area outside each trailer door and handle shipments as pallets using forklifts. The insights generated in this research thus apply to a specific class of cross docks, which is quite commonly used in practice (Napolitano 2000).

The rest of this article is organized as follows. The next section begins with a literature review, followed by a description of a simulation model. The experimental factors are then described. The experimental design proposes two full-factorial experiments and describes the performance measures collected to analyze the performance of cross docks. The results are then analyzed and discussed. Finally, the conclusions summarize the findings and managerial implications.

\section{LITERATURE REVIEW}

According to Gue (2007), warehousing and cross docking are part of a multi-echelon distribution continuum. Traditionally, the goal of warehousing is to improve customer service by storing inventory in a warehouse near to the customers. As an alternative, cross docking is a newer strategy proposed to eliminate the storage cost by moving inventory quickly through a cross dock without storage to the customers. However, cross docking is not an elixir for all distribution problems. Waller, Cassady, and Ozment (2006) discussed situations where cross docking is not beneficial. They showed that cross docking may require extra inventory at the stores to avoid stock-outs. Specifically, as the number of stores increases, the benefit of cross docking decreases. It is thus obvious that the benefits of cross docking versus warehousing, must be compared based on the total cost incurred in a supply chain; and the vast amount of literature related to managing inventory in a multi-echelon system remains relevant. Williams and Tokar (2008) provided an excellent review of these models. The exemplary work includes Federgruen (1993), Federgruen, Prastacos, and Zipkin (1986), Federgruen and Zipkin (1984), Huq, Cutright, Jones, and Hensler (2006); Masters (1993), and Nozick and Turnquist (1998). For distribution systems using only cross docks and no storage of inventory, one can refer to the works by Galbreth, Hill, and Handly (2008), Gümus and Bookbinder (2004), and Sung and Song (2003).

This research is on the internal operations of cross docks. Our literature review is thus focused on literature related to the internal operations of cross docks. Cross docks can exist in different forms (Napolitano 2000). Bartholdi, Gue, and Kang (2001) suggested two ways to classify cross docks. One way is to classify them as preand post-distribution cross docks. In a pre-distribution cross dock (Figure 1), the destinations R1, R2 and R3 are predetermined and labeled on the shipments before they arrive at the cross dock. Workers can then transfer such shipments directly from inbound to outbound trailers bound for R1, R2 and R3. In a post-distribution cross dock (Figure 2), inbound freight arrives without a pre-determined destination, and workers at the cross dock assign the destinations to the shipments. This offers the advantages of postponing the final destinations, maintaining confidentiality of the final destinations, and delaying the performance of certain value-adding activities, such as price-tagging and re-packing, at the cross docks. A post-distribution cross dock thus normally requires more floor space to stage freight for these value-adding activities. 
FIGURE 1

\section{A PRE-DISTRIBUTION CROSS DOCK}

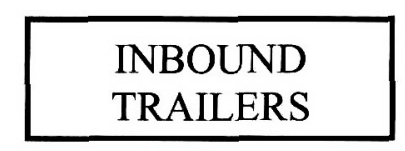

OUTBOUND

TRAILERS

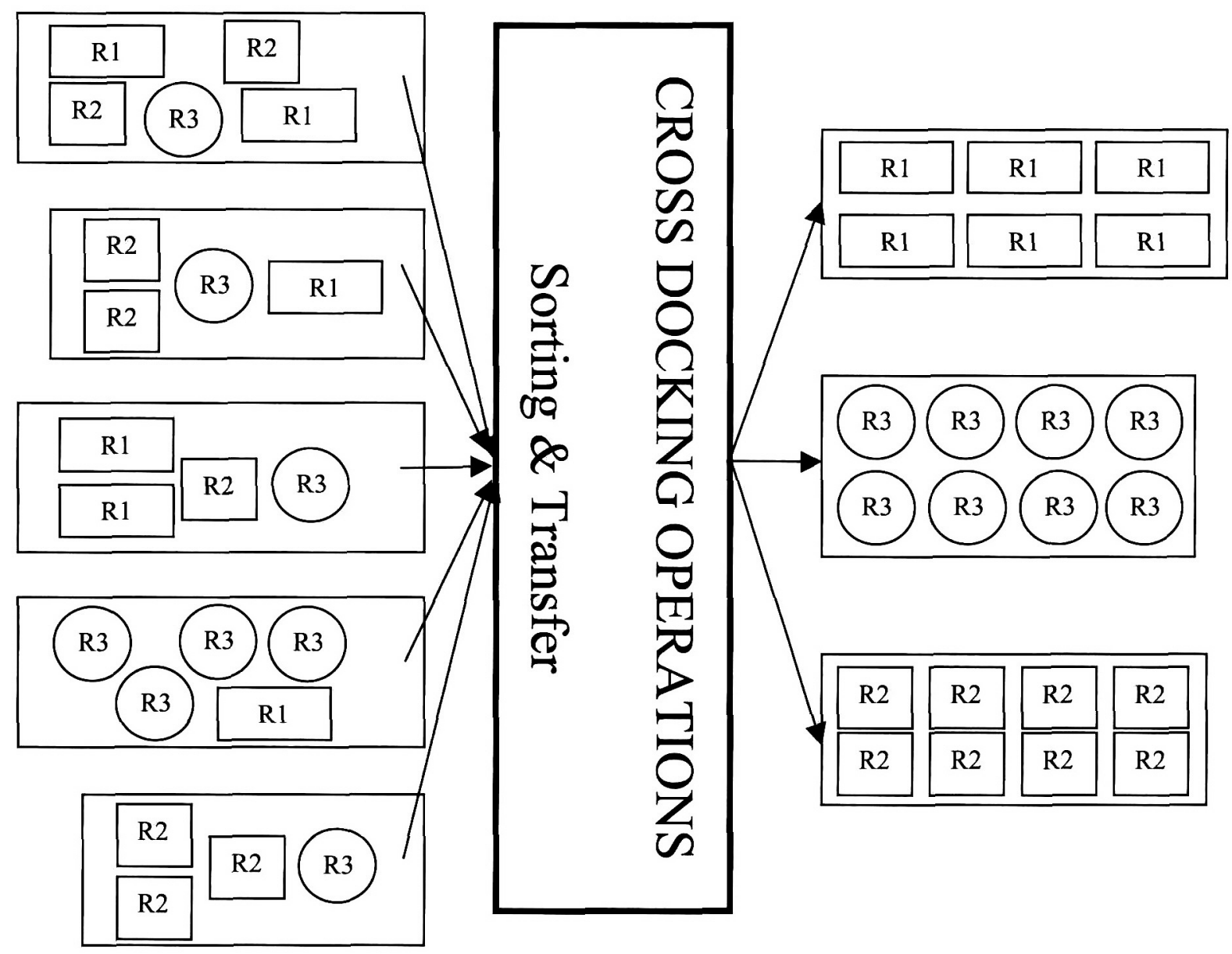


FIGURE 2

\section{A POST-DISTRIBUTION CROSS DOCK}

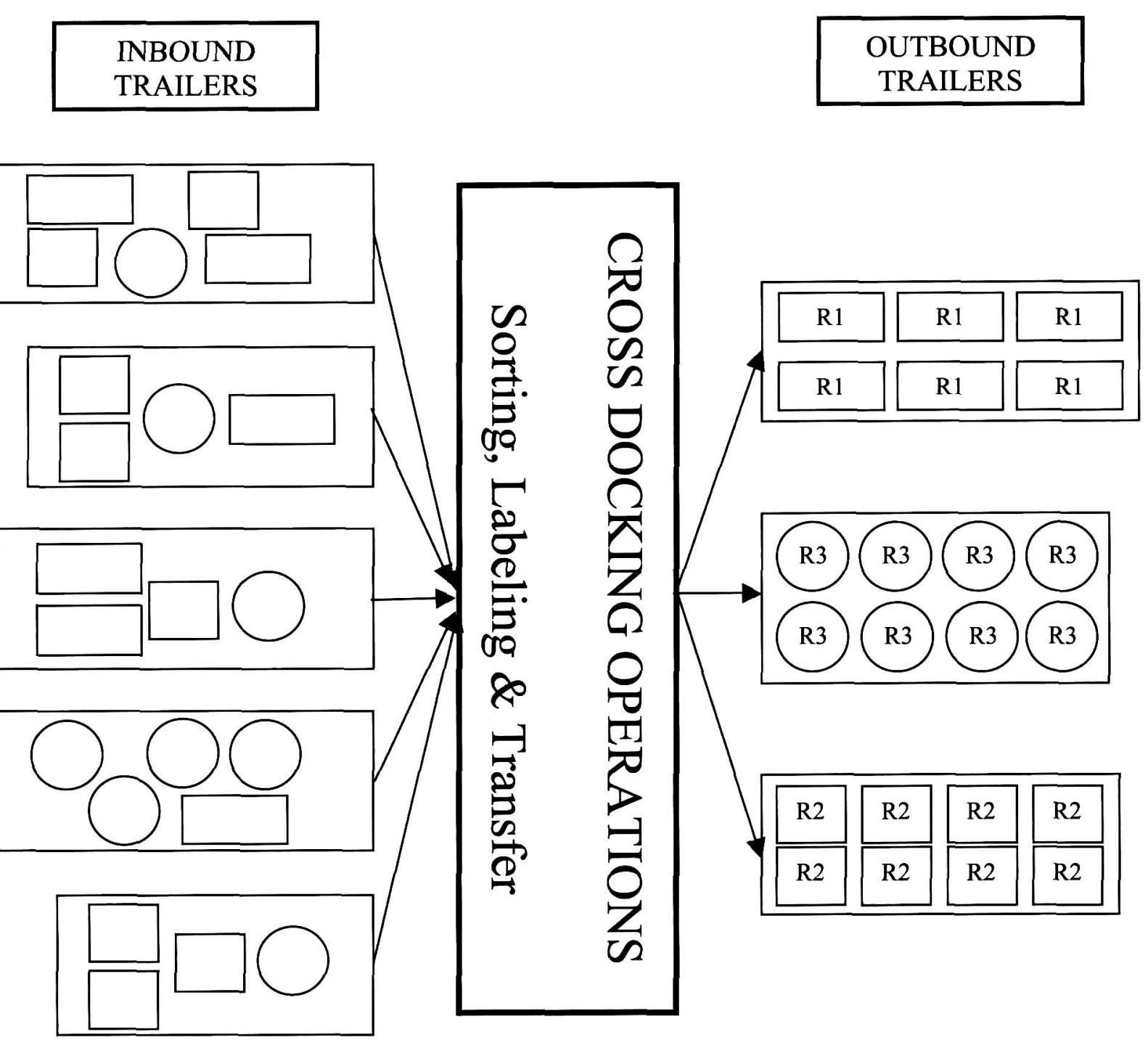

A second way to classify cross docks is according to the method of staging freight. There are the single-stage, two-stage, and free-staging methods. In a single-stage cross dock, pallets are unloaded and placed into staging lanes corresponding to either the receiving or shipping doors (Figure 3). Inbound pallets are normally staged into lanes that correspond to the receiving doors when final destinations are still unknown on arrivals. However, if the arriving pallets are already pre-packed or can be re-sorted (easily at the receiving doors) for different destinations, the pallets are probably better staged into lanes that correspond to shipping doors. Staging pallets according to shipping doors offers the shipping crew a better visibility of the pallets waiting at each shipping door, and may facilitate a better utilization of trailer space during loading. 


\section{FIGURE 3}

\section{A SINGLE-STAGE CROSS DOCK}

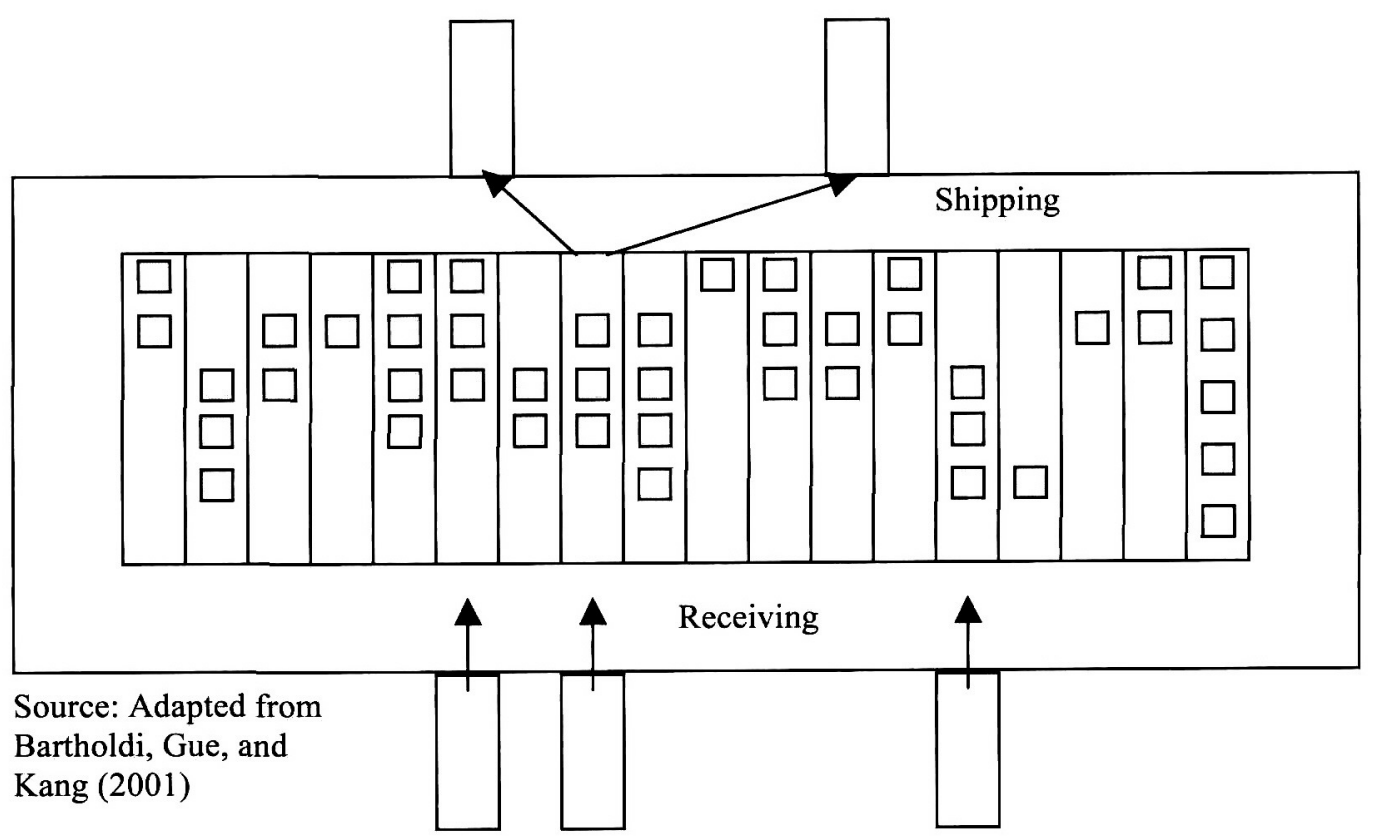

An alternative to a single-stage cross dock is a two-stage cross dock (Figure 4). A two-stage cross dock offers the advantage of allowing workers in the center aisle to re-sort or re-pack pallets from the staging lanes that correspond to the receiving doors into the staging lanes that correspond to the shipping doors. At the receiving doors, pallets are unloaded directly into the staging lanes that correspond to the receiving doors. The pallets can then be resorted and re-packed. A two-stage cross dock thus offers the advantage of re-packing shipments from the receiving lanes into tightly packed pallets and better visibility to load the pallets tightly into the outbound trailers. The disadvantages are each pallet is handled one more time, more floor space is needed to accommodate the additional center aisle and staging lanes, and a larger cross dock, which may result in a larger travel time and effort.

A cross dock with free staging does not use any queue where pallets are placed at one end and pulled from the other. Rather, a free staging area is reserved next to each receiving, shipping, and/or both doors. For example, in the free staging area of each receiving door, pallets can be unloaded from inbound trailers, re-sorted and re-packed, before they are moved to the shipping doors. Similarly, pallets can also be re-sorted or staged in the free staging area of each shipping door before they are loaded onto outbound trailers. Besides the 1-stage, 2-stage and free-staging cross docks, Napolitano (2000) suggested that incoming shipments can also be re-directed into a separate re-sorting and re-packing area before they are transferred back to the shipping doors.

While various reasons and benefits have been cited for staging freight and performing post-distribution activities in a cross dock, most managers will argue for a pre-distribution cross dock. In other words, the distribution activities are done before the shipments are sent to a cross dock, so that the costs of double handling and staging freight in a cross dock (which is a waste in Just-in-Time terminology) are eliminated.

An analysis of a cross dock is further complicated by the existence of cross docks of various kinds, shapes and configurations. Bartholdi and Gue (2004), for example, examined different shapes of cross docks. They showed that the best shape depends on the number of doors, ratio of receiving to shipping doors, and pattern of freight flow in a cross dock. They showed that a bad design can increase both the labor costs and level of congestion in a cross dock, and an I-shape cross dock is best for cross docks with fewer than 150 doors. A T-shape is best for cross docks with 150 to 250 doors, and H-shape is best for cross docks with more than 250 doors. Nevertheless, both Bartholdi and Gue (2004) and Napolitano (2000) reported that most cross docks are I-shape, consisting of a long, narrow building with doors spaced evenly around its perimeter. 
FIGURE 4

A TWO-STAGE CROSS DOCK

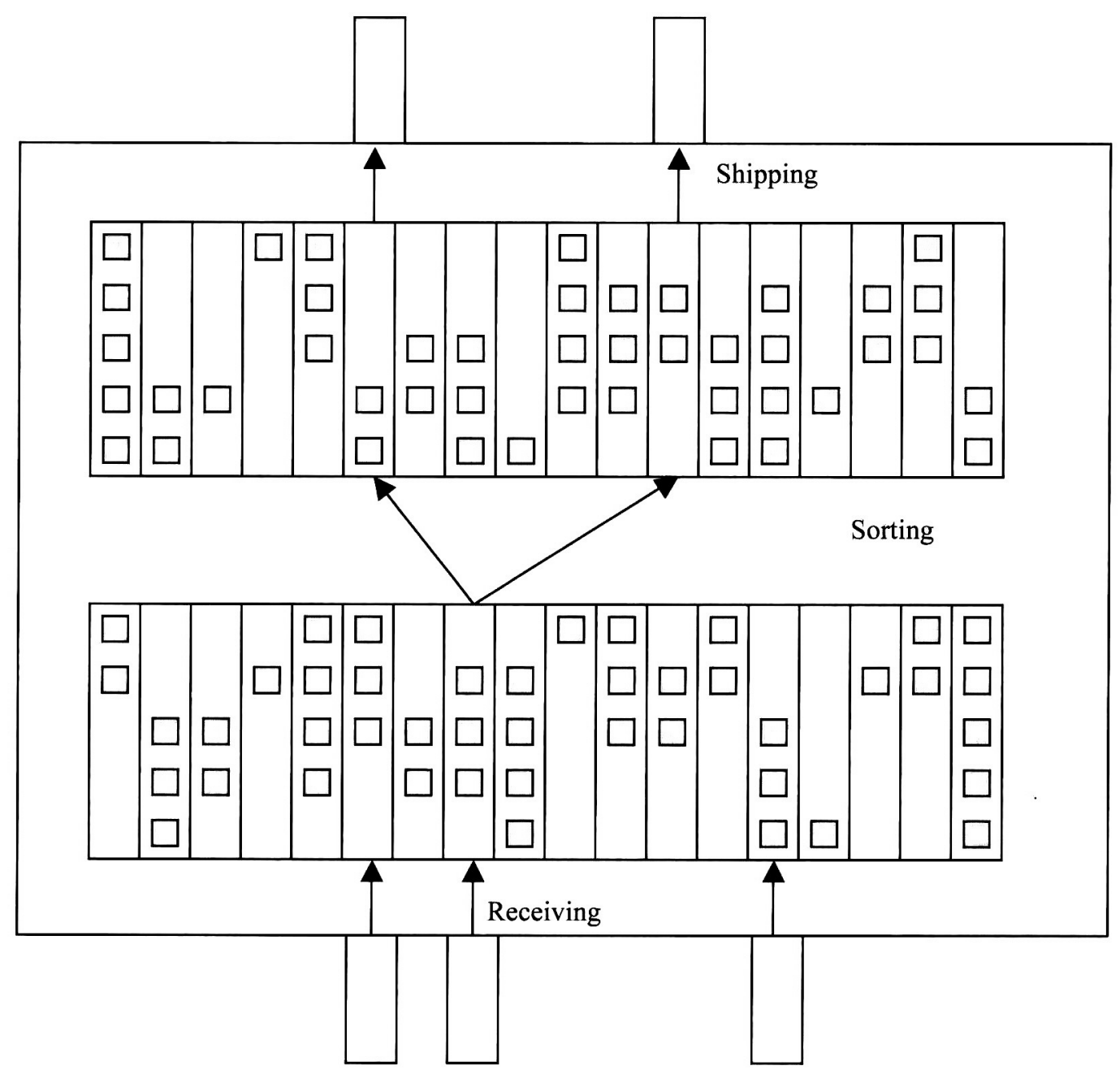

Source: Adapted from Bartholdi, Gue, and Kang (2001)

Other studies on cross docks are focused mainly on reducing the cost of transferring freight from receiving to shipping doors. Tsui and Chang $(1990,1992)$ proposed models to assign inbound and outbound trailers to the right doors, such that the total distance traveled by forklifts to transfer shipments from inbound to outbound trailers is minimized. Unlike Tsui and Chang $(1990,1992)$, Gue (1999) examined an environment where trailers arrive dynamically over time. He therefore proposed a real-time scheduling procedure to assign inbound trailers to doors. He showed that his procedure can reduce labor costs by $15 \%$ to $20 \%$ compared to a first-come, first-serve policy. Wang and Regan (2008) also proposed and compared four real-time algorithms to assign trailers to doors. Their objective was to reduce the total time freight spent in a cross dock.

As a further enhancement, Bartholdi and Gue (2000) defined a more accurate model to measure the labor costs required to transfer freight from inbound to outbound trailers. Their model minimizes not only the total travel cost between doors, but also the total cost of forklift congestion, dragline congestion, and space congestion at the doors. They validated their model in a real cross dock and reported an improved productivity of more than $11 \%$. 
While the above studies implicitly assumed that shipments are transferred directly between inbound and outbound trailers, Bartholdi, Gue, and Kang (2001) examined cross docks where pallets are staged before they are loaded onto outbound trailers. They compared two methods of staging freight: staging pallets on the floor; versus staging pallets in a flow rack. They suggested that the value of a flow rack is probably too small to justify its use. As a further extension, Gue and Kang (2001) compared the throughput of single-stage and two-stage cross docks (see Figures 3 and 4). They showed that a two-stage system produces lower throughput and labor productivity than an equivalent single-stage system.

Our literature review shows that past research has examined cross docks assuming either freight staging or no freight staging. There is no comparison of freight staging versus no freight staging on the performance of cross docks. While many authors, such as Allegri (1993), Mulcahy (1994), Napolitano (2000), and Tompkins, White, Bozer, and Tanchoco (2003), supported the elimination of staging and double handling in cross docks, the value of transferring shipments directly from inbound to outbound trailers has not been tested rigorously. In this research, we thus compare the value of transferring shipments directly, versus indirectly from inbound to outbound trailers as one of the experimental factors.

While our review shows that cross docks exist in different forms, our objective is to focus our study on a specific class of cross docks that appeals to a larger audience. We therefore model the I-shape cross dock, as it is the most common in practice (Bartholdi and Gue 2004; Napolitano 2000). We also model using forklifts to move shipments in the cross dock as Napolitano (2000) has suggested. Forklifts are the most versatile and common material handling system in cross docks. We investigate the impact of various factors and decisions on the performance of cross docks, and present the simulation model of the cross dock and the experimental factors in the next two sections.

\section{SIMULATION MODEL}

Figure 5 shows an I-shape cross dock with 12 doors. One side of the cross dock is zoned for receiving, while the other is zoned for shipping. As inbound trailers arrive at the cross dock, each trailer is assigned to an available receiving door. The trailer is then unloaded; and its shipments are transferred and loaded, either directly or indirectly onto trailers parked at shipping doors. Once an outbound trailer is fully loaded, it is hauled away and replaced with an empty trailer.

While a receiving door is assigned over time to inbound trailers from different origins, each shipping door is often assigned permanently to outbound trailers going to the same destination. This is to reduce the chance of moving and loading shipments into the wrong door (i.e. destination) as workers commit to memory the location of each destination to a permanent shipping door.

Forklifts are typically used to unload, move and load pallets from inbound to outbound trailers. One or more forklifts may be assigned to each receiving door at the same time. Figure 5 shows an example of a forklift (shown as a dark square) assigned to receiving door R1. This forklift will wait in lane QR 1 for access into R1. If the staging area and trailer at R1 are not occupied by another forklift retrieving pallet, the forklift in lane QR1 will travel along path p1 into R1 to retrieve a pallet. Assuming that the pallet retrieved is for shipping door S4, the forklift will then move the pallet along path $\mathrm{p} 2$ and turn into lane QS4. If the staging area and outbound trailer at S4 are occupied by another forklift delivering a pallet, the forklift will wait in lane QS4. If door S4 is clear, the forklift waiting in the lane QS4 will move along path p3 into S4. Once it has unloaded its pallet, the forklift will travel along path p4, turn back into lane $\mathrm{QR} 1$, and wait to retrieve another pallet at $\mathrm{R} 1$, its assigned receiving door.

Simulation models of cross docks with 24 and 96 doors, similar to Figure 5, were built using the NETWORKS function of ARENA (Kelton, Sadowski, and Sturrock 2004) to model the travel and congestion along the aisles and lanes when forklifts block or obstruct one another. The physical dimensions of the cross docks and the operating characteristics of the forklifts were defined based on a survey of trade publications (Mulcahy 1994; Napolitano 2000; Tompkins et al. 2003) and visits to actual cross docks. 
FIGURE 5

\section{MODEL OF CROSS DOCK}

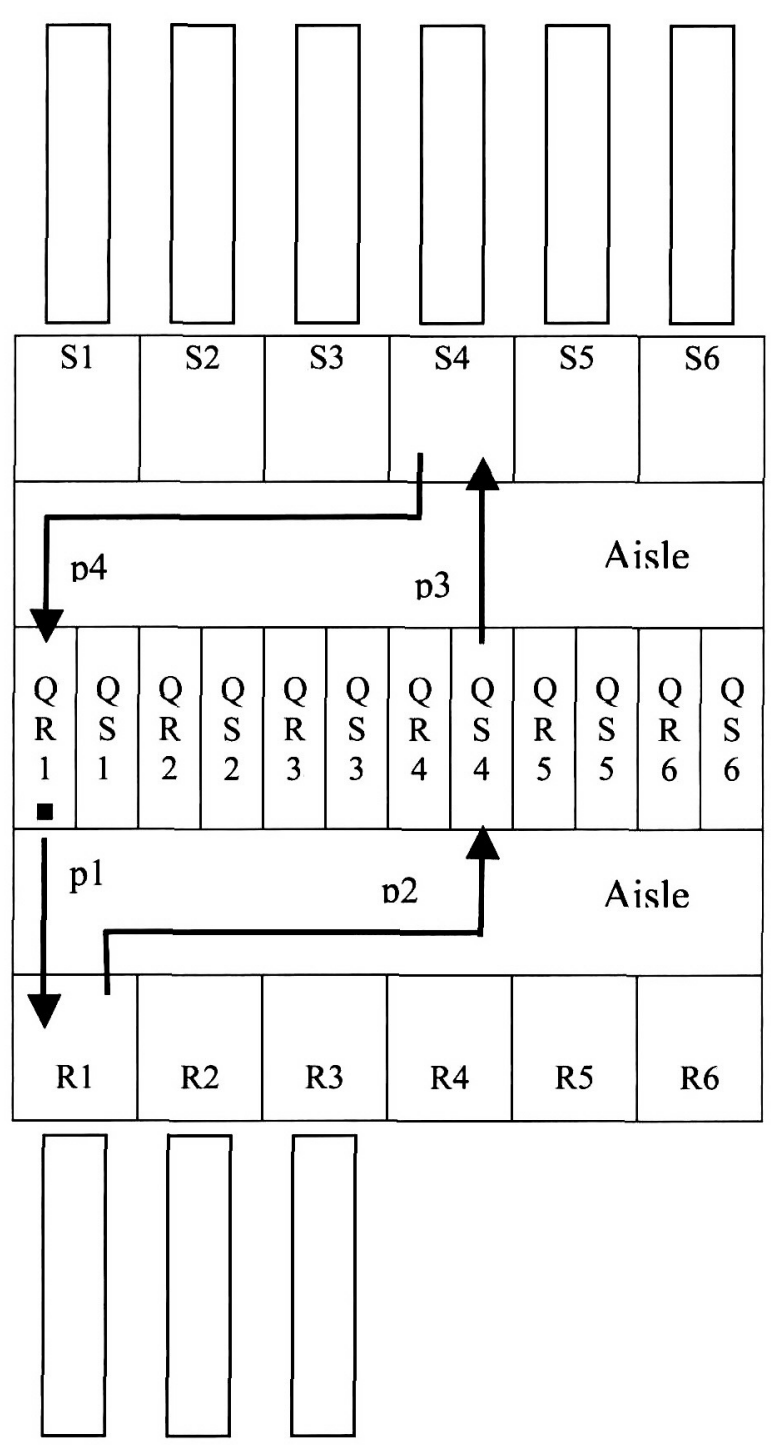

The distance between adjacent doors is set at 16 feet. At each door, there is a free staging area with parked trailer which accommodates only one forklift at a time. When a staging area or its associated trailer is occupied, incoming forklifts wait for access in a lane. The width and length of each lane are set at eight and 24 feet respectively. Each lane can thus accommodate a maximum queue of three forklifts, as each forklift is typically eight feet long. There are two aisles running along the length of the cross dock, one along the shipping doors and the other along the receiving doors. The width of each aisle is set at 16 feet, wide enough for two-way travel along its length.

Our model assumed an infinite supply of pallets at the receiving doors for forklifts to unload from inbound trailers. Similarly, it also assumed that outbound trailers are always available at the shipping doors, such that pallets that are ready to be loaded are never delayed because of a lack of trailers. This is a standard assumption used in past research to determine the maximum capacity of a system to handle a continuous supply of work.

Discussions with operators of cross docks suggested that loading a pallet onto a trailer is twice as difficult as unloading it from a trailer. The mean times for loading a pallet onto a trailer from its staging area and for unloading 
a pallet from a trailer to its staging area are then estimated to be 3.0 minutes for loading and 1.5 minutes for unloading. The tasks to pick up (or place) a pallet at a receiving (or shipping) staging area are much easier, and the mean time is estimated to be 0.5 minutes. As the service times for these tasks are fairly variable, we follow Banks, Carson, Nelson, and Nicol's (2004) recommendation and generate these service times using exponential distributions with the mean values estimated above.

The existence of blocking and congestion in the model (and in practice) can have a significant impact on performance. For example, when two forklifts are waiting to unload pallets directly from a trailer at the same receiving door, only one forklift can drive onto the trailer to unload a pallet, while the other forklift must wait and incur idle time. Delays can also occur when traffic jams occur along the aisles. There are forklifts moving along the aisles, as well as forklifts crossing the aisles, as they move into or out of the lanes and staging areas. The queue of forklifts can also spill into the aisles since the queuing lanes can accommodate a maximum of three forklifts. This can happen at lanes leading into shipping doors. But it does not happen at lanes leading to receiving doors, since the maximum number of forklifts assigned to a receiving door in our model is restricted to three. Consequently, even though the speed of a forklift is assumed and fixed at four miles per hour, the actual travel time is uncertain when blocking occurs along the travel paths.

We assumed that the cross dock was operated round the clock. The batch mean method was used to gather data consisting of 30 batches, each of 100 hours. A warm up period of 200 hours was sufficient to eliminate the initial transience.

\section{FACTORS IN THE SIMULATION}

Our visits and literature review suggested a number of managerial decisions and factors that could affect the performance of cross docks. These decisions and factors are described in the following sections.

\section{Pallet Handling}

To move pallets between inbound and outbound trailers, a manager has the options of unloading, moving, and reloading pallets directly or indirectly between the inbound and outbound trailers. Figure 5 shows a cross dock with a free staging area at each door. The option thus exists to move pallets between staging areas, instead of directly between trailers.

Unloading a pallet from a trailer into the staging area at the receiving door is denoted by US (unload into staging area), while unloading a pallet from a trailer and moving it directly to the shipping side of the dock is denoted by UT (unload trailer directly to shipping). Similarly, if a shipping trailer is loaded from the shipping staging area, it is denoted by LS (load from staging area), and if it is loaded directly from the receiving area it is called LT (load trailer directly after pallet arrives from the receiving area without staging it in the shipping area).

The four options on how pallets are unloaded, moved, and loaded are shown in Table 1. Option 1 (i.e. UT/LT) is to unload each pallet, one at a time, directly from an inbound trailer, move, and re-load the pallet directly onto an outbound trailer. Most Just-in-Time and logistics gurus would advocate this option to eliminate double-handling and the wasted action of "pallet touching the floor."

TABLE 1

STAGING OPTIONS

\begin{tabular}{|c|c|c|}
\hline Option & Staging at Receiving Door & Staging at Shipping Door \\
\hline 1 & No (UT) & No (LT) \\
\hline 2 & Yes (US) & No (LT) \\
\hline 3 & No (UT) & Yes (LS) \\
\hline 4 & Yes (US) & Yes (LS) \\
\hline
\end{tabular}


Option 2 (i.e. US/LT) is to unload all pallets from inbound trailers and stage them at staging areas near their respective receiving doors before cross docking. These pallets are assumed to be unloaded by a separate team of material handlers. Cross docking forklifts then pick up each pallet staged near its receiving door, move, and load the pallet directly onto outbound trailers. For Option 3 (i.e. UT/LS), cross docking forklifts unload pallets directly from inbound trailers, and then move and stage the pallets in staging areas at their respective shipping doors. These pallets are then also assumed to be loaded onto outbound trailers by a separate team of material handlers. Both Options 2 and 3 require an additional "pick-and-put" action at the receiving and shipping doors, respectively.

Option 4 (i.e. US/LS) is to stage pallets at both receiving and shipping doors. Cross docking forklifts move each pallet between staging areas of receiving and shipping doors, instead of directly between inbound and outbound trailers. This option requires two additional "pick-and-put" actions for each pallet, once at a receiving door, and the other at a shipping door. These additional actions are also assumed to be done by a separate team of material handlers, and not by the cross docking forklifts.

\section{Freight Mix}

Each incoming trailer normally brings in pallets for various destinations. Bartholdi and Gue (2004) reported that the flow rates to different destinations typically differ by a factor of two to 10 . Two pallet mixes are examinedUniform and Biased. Under the uniform pallet mix, each pallet received is randomly assigned a destination with equal probability. Under the biased pallet mix, each pallet is randomly assigned a destination such that $70 \%$ of the pallets are directed to $30 \%$ of the destinations. Figure 6 , for example, shows the flow rates to 12 destinations under the biased pallet mix. Each destination is served by a specific shipping door. Destination (shipping) doors are shown above the cross dock while receiving doors are shown below the cross dock. The higher the height of the bar in the figure, the higher is the volume of the traffic through that shipping door. Although the assignment of a door to a destination is different in each of the four diagrams (this is related to another factor setting, door layout), a few shipping doors always account for a majority of the traffic volume. If the pallet mix is uniform, every shipping door will have the same mean volume of traffic (height of the bar). Uniform mix is designated by UL (uniform load) and biased mix is denoted by BL (biased load).

\section{Number of Forklifts}

To move pallets between receiving and shipping, a manager can assign different numbers of forklifts to each open receiving door. As in most cross docks, each forklift is permanently assigned to a receiving door to move pallets from its assigned door to any shipping doors. When more forklifts are assigned, it will obviously increase congestion and affect the movements of pallets in the cross dock. The numbers of forklifts assigned to each open receiving door are examined at one, two and three forklifts per door.

As this is an initial study, we assume that all forklifts are assigned to the cross docking function only. For example, in the pallet handling Option 2 (i.e. US/LT), where staging occurs at the receiving doors, it is assumed that the movement of pallets between the incoming trailers and receiving staging areas is done by another crew outside this simulation. In Option 2, our simulation is focused only on cross docking pallets from the receiving staging areas directly to the trailers in the shipping area (since there is no staging in the shipping area in Option 2). Similarly, in Options 3 and 4, it is assumed that any transfer between trailers and staging areas is done by a different crew outside this simulation. This assumption helps us defer the need to examine how forklifts are shared between the staging and cross docking functions. In cross docks where the material handling resources are shared, future research can provide the answers.

\section{Number of Receiving Doors}

Bartholdi and Gue (2004) reported that the fraction of doors open as receiving doors in practice ranges from 5 $\%$ to $50 \%$. In our study, $50 \%$ of the doors are reserved for shipping and the other $50 \%$ for receiving. To examine the impact of opening different number of receiving doors on performance, we examine the percentage of receiving doors open for inbound trailers at $33 \%, 50 \%$, and $100 \%$ of all available receiving doors. As an example, for a cross dock with 12 receiving doors, four, six, or all 12 receiving doors can be used simultaneously. If the same cross dock has 12 forklifts, three, two, or one forklift can be assigned per receiving door when four, six, or all 12 receiving doors are used respectively. 
FIGURE 6

\section{LAYOUTS OF CROSS DOCK}

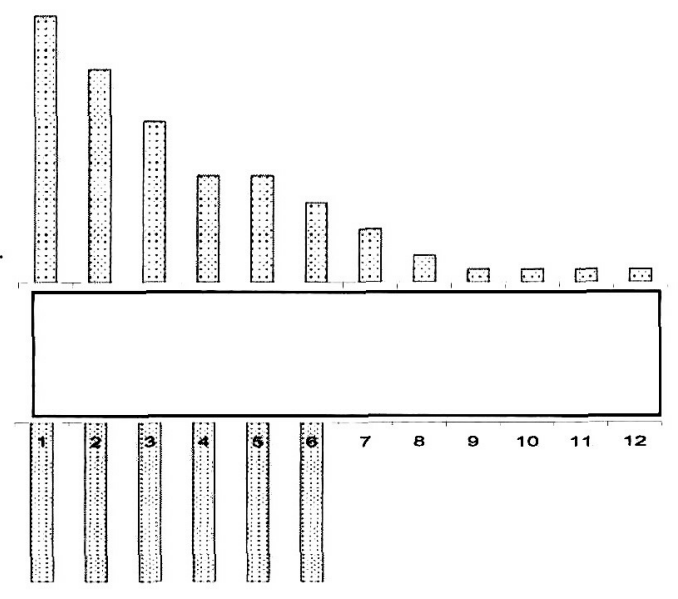

LALS

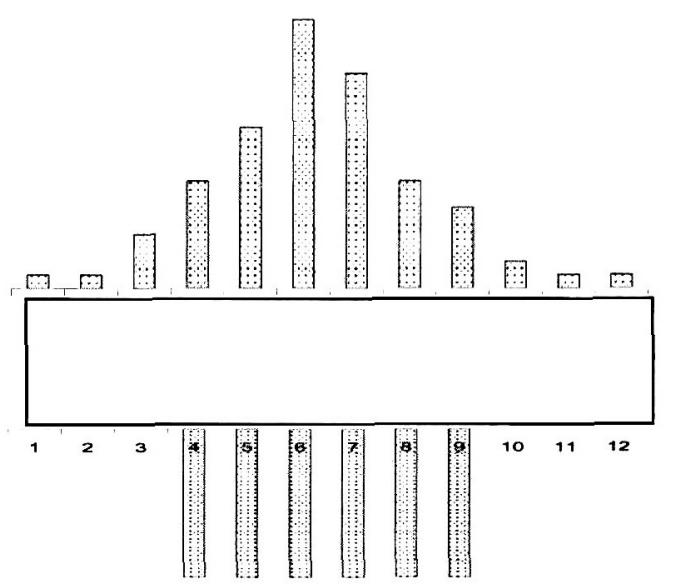

CACS

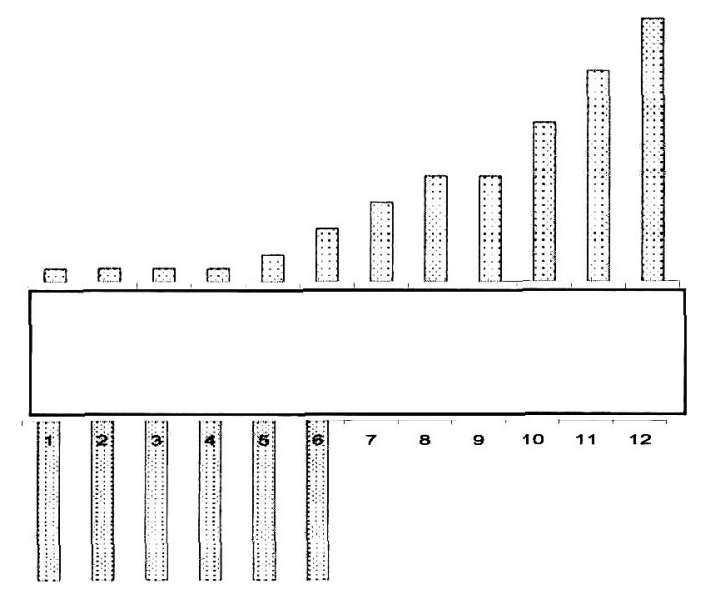

LARS

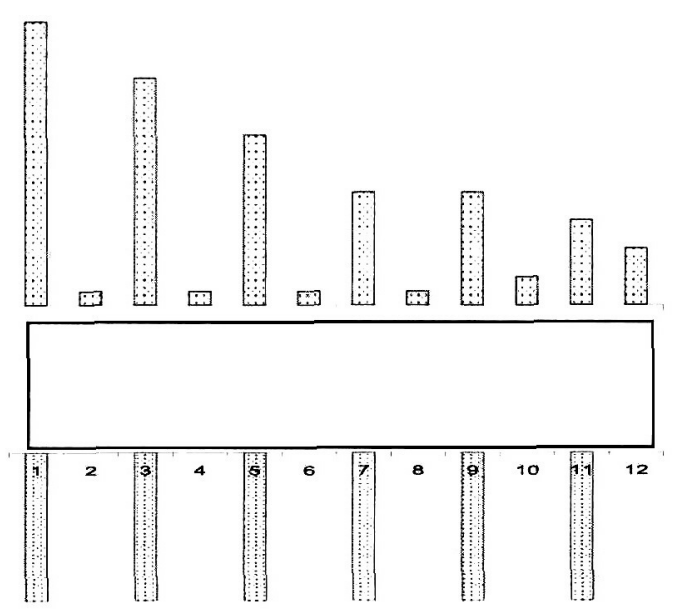

SASS

Discussions with cross dock managers suggested that many are interested in opening fewer receiving doors. One reason is to reduce the number of security and receiving inspection points by opening fewer doors. A second reason is that one shipping door is normally assigned to one destination while the same receiving door can be used by inbound trailers from different origins. A third reason is fewer receiving doors are normally needed as the congestion at receiving doors is usually more predictable than that at shipping doors. In other words, congestion at each receiving door is limited by the maximum number of forklifts assigned to it, while the congestion at each shipping door is more uncertain, as all forklifts may visit the same shipping door at the same time. A fourth reason is opening fewer receiving doors reduces the mean travel distance to the shipping doors. Consequently, the decision on 
opening the right number of receiving doors, to balance the effect of travel distance and door congestion, is worth examining.

\section{Door Layout}

The decision on the door layout will obviously affect the proportions of time that forklifts will spend on traveling between doors, unloading, and loading pallets. It will also likely affect the level and pattern of congestion and waiting in a cross dock. This decision is thus examined.

As mentioned previously, most cross docks do not use all receiving doors simultaneously. Figure 6 shows a cross dock that uses $50 \%$ of all receiving doors with four combinations of door layouts-LALS, LARS, CACS, and SASS. LALS (Left Arrival and Left Shipping) layout uses receiving doors from left to right and assigns destinations with the heaviest traffic to shipping doors from left to right. This layout helps minimize the travel distance between receiving and shipping doors. However, more forklifts are expected in the left part of the cross dock, which may increase congestion along the aisles and the actual time to transfer pallets between receiving and shipping.

LARS (Left Arrival and Right Shipping) layout uses receiving doors from left to right and assigns destinations with the heaviest traffic to shipping doors from right to left. This layout increases the travel distance between receiving and shipping doors. It, however, helps to divert forklifts away from open receiving doors and may help reduce congestion along the aisles and actual time to transfer pallets between receiving and shipping.

CACS (Centre Arrival and Centre Shipping) layout uses the receiving doors in the central part of the cross dock. Destinations with heavier traffic are also assigned to shipping doors nearer to the central portion of the cross dock. This layout minimizes the travel distance between receiving and shipping doors, but heavy congestion may occur along the aisles in the central part of the cross dock.

SASS (Spread Arrival and Spread Shipping) layout attempts to spread the traffic as evenly as possible along the entire cross dock, and possibly minimize congestion along the aisles. The travel distance between doors may increase, but the reduced congestion along the aisles may help to moderate the negative effect of longer travel distance.

\section{Size of Cross Dock}

The size of a cross dock will obviously affect the proportions of time spent on traveling between doors, unloading, and loading pallets. The choice of the right decisions, such as the method of pallet handling and door layout, may also depend on the size of the cross dock. We thus examine small and large cross docks with 24 and 96 doors respectively.

\section{EXPERIMENTAL DESIGN}

To conduct a full-factorial experiment with six factors as a single experiment is too unwieldy. We therefore conducted some pilot simulation runs to isolate the factors that do not interact into two smaller full-factorial experiments.

\section{Experiment 1: Impact of Door Layouts and Number of Forklifts}

Experiment 1 examines the impact of door layouts and number of forklifts on moving pallets directly or indirectly between inbound and outbound trailers. Table 2 tabulates the experimental factors in Experiment 1 . Our pilot simulation runs showed that the same door layout performs best regardless of the size of the cross dock. The pilot runs also showed that opening the right number of receiving doors has little impact in a small cross dock. To limit the size of Experiment 1, the size of a cross dock and the number of open receiving doors are thus fixed at 24 and 6 doors, respectively. As most cross docks use fewer receiving than shipping doors, we use $50 \%$ of the receiving doors (i.e., six receiving doors are used and the other six are not used) and $100 \%$ of the shipping doors (i.e., all 12 shipping doors are used). Since each receiving door is assigned either one or two forklifts in Experiment 1 , there are a total of either six or 12 forklifts in the cross dock with six open receiving doors. 
TABLE 2

\section{EXPERIMENT 1}

\begin{tabular}{|l|l|}
\hline \multicolumn{1}{|c|}{ Factors } & \multicolumn{1}{c|}{ Factor Levels } \\
\hline Pallet Handling & US/LS, UT/LS, US/LT, UT/LT \\
Freight Mix & Uniform (UL), Biased (BL) \\
Door Layout & CACS, LALS, LARS, SASS \\
Total Number of Forklifts & 6,12 \\
& \\
Size of Cross Dock & Fixed at 24 doors \\
Number of Receiving Doors Open & Fixed at 6 doors (i.e., 50\% open) \\
\hline
\end{tabular}

\section{Experiment 2: Impact of Number of Open Receiving Doors and Size of Cross Dock}

Experiment 2 examines the impact of number of open receiving doors and size of a cross dock on moving shipments directly or indirectly between inbound and outbound trailers. Table 3 tabulates the experimental factors in Experiment 2. The best door layout identified in Experiment 1 is used in this experiment. The total number of forklifts used in this experiment is also fixed, such that one forklift is available for each receiving door when all receiving doors are open. Thus, in the small cross dock with 12 forklifts and 12 receiving doors, one forklift is assigned to each receiving door if $100 \%$ of the receiving doors are open. If only $50 \%$, i.e., six receiving doors are open, each door is allocated two forklifts. If only $33 \%$, i.e., four receiving doors are open, each door is allocated three forklifts. Similarly, in the large cross dock with 48 forklifts and 48 receiving doors, $33 \%, 50 \%$ and $100 \%$ open receiving doors translate to three, two, and one forklift per receiving door.

TABLE 3

\section{EXPERIMENT 2}

\begin{tabular}{|l|l|}
\hline \multicolumn{1}{|c|}{ Factors } & \multicolumn{1}{c|}{ Factor Levels } \\
\hline Pallet Handling & US/LS, UT/LS, US/LT, UT/LT \\
Freight Mix & Uniform (UL), Biased (BL) \\
Number of Receiving Doors Open & $33 \%, 50 \%, 100 \%$ \\
Size of Cross Dock & 24,96 doors \\
& \\
Door Layout & Fixed at CACS \\
Total Number of Forklifts & Fixed at 12 for small and 48 for large cross dock \\
\hline
\end{tabular}

\section{Performance Measures}

Two measures of performance were collected: (1) Mean Hourly Throughput per Forklift (MTF) measures the mean number of pallets moved per hour between receiving and shipping by a forklift; and (2) Mean Handling Time per Pallet (MHP) measures the mean amount of labor minutes required to move one pallet from inbound to outbound trailer. While MTF is a measure of the capacity of a cross dock to handle pallets from receiving to shipping, MHP is a measure of the total effort required to move one pallet from an inbound to an outbound trailer. To compute the mean handling time per pallet (MHP), different amounts of additional handling time are added to the time observed during simulation to move a pallet from receiving to shipping. The amount of additional handling time added depends on the option of pallet handling. For example, the US/LS handling option moves each pallet from the staging area of a receiving door to the staging area of a shipping door. In this case, another 1.5 labor minutes to unload a pallet from inbound trailer to staging area and 3.0 labor minutes to load a pallet from staging area to outbound trailer are added to the simulation result to compute the mean handling time per pallet. In other words, we assume that unloading pallets at each receiving door (from an inbound trailer to its staging area) is assigned to a single material handler with sufficient space in the staging area for the material handler to maneuver 
without "crashing" into or blocking the cross-docking forklift picking pallets from the same area. Similarly, loading pallets at each shipping door (from its staging area into an outbound trailer) is also assigned to a single material handler with no blocking and starving. In other words, the material handler is assigned to a shipping door only when a buffer of pallets exists at its staging area such that the material handler will not starve while loading pallets onto an outbound trailer.

\section{RESULTS}

Analysis of variances (ANOVA) was used to identify the significant interactions among the factors examined in the two full-factorial experiments suggested above. In both experiments, the highest-order interactions were statistically significant. The results for all factor combinations were thus plotted and analyzed below.

\section{Mean Hourly Throughput per Forklift}

Figure 7 shows the four sub-plots of mean hourly throughput per forklift (MTF) in Experiment 1. Each subplot shows the MTF of different door layouts for one of the four pallet handling options. Pair-wise comparison of the subplots US/LS against UT/LS (and US/LT against UT/LT) shows that unloading pallets indirectly produces a larger MTF than unloading directly, because of a shorter unloading time and reduced congestion at the receiving doors. Similarly, comparing the sub-plots US/LS against US/LT (and UT/LS against UT/LT) shows that loading pallets indirectly also always produces a larger MTF than loading directly because of a shorter loading time and reduced congestion at the shipping doors. This occurs because a forklift spends an average of 3.0 minutes loading a pallet directly onto a trailer, while placing a pallet in the staging area takes an average of only 0.5 minutes. Thus, by staging pallets at the shipping doors, each forklift can quickly do its work and return. However, by removing staging at the shipping doors, each forklift takes a longer time to load an actual trailer, since only one forklift can drive onto a trailer at a time to load a pallet directly, increasing the queuing and congestion at the shipping doors. Consequently, the option of indirect unloading and indirect loading of pallets (i.e., letting the actual unloading and loading between trailers and staging areas done by a separate material handling team) increases the ability of a cross dock to handle a higher throughput. This shows that while many experts feel that less handling is always better, given how a cross dock works, it might be better to incur the additional handling by staging freight at the doors to reduce the door congestion. This reduced congestion enables the cross dock to handle a higher throughput which, in turn, may sufficiently offset the cost of the extra material handling.

In our simulation, the maximum number of forklifts at each receiving door is limited by the maximum number assigned to it. However, the maximum number of forklifts waiting at a shipping door can be all forklifts in the cross dock, as all forklifts can potentially carry pallets meant for the same destination. The congestion at shipping doors is thus generally worse than receiving doors. This is due to the unpredictability of pallet arrivals at the shipping doors as a result of the combined effects of the volume unpredictability of destinations (especially with skewed loads), and the unpredictability of waiting, picking, placing, and travel times along the aisles. Loading outbound trailers directly, thus wastes much labor time, since the queuing and congestion at the shipping doors are generally significant. In Figure 7, it is seen that in options where direct loading is done (US/LT and UT/LT), the congestion at the shipping doors is so great that it does not matter whether a better layout is used; the MTF is about the same for all layouts. In contrast, when staging is done at the shipping areas (US/LS and UT/LS), the effect of a better layout is greater, since the gains in lesser travel times are less offset by the congestion at the shipping doors due to indirect loading. From a practical perspective it appears that managers might have to incur the additional material handling cost of staging at the shipping doors to realize the benefits of a good layout, such that the gains in lesser travel times are not totally offset by congestion at the shipping doors. 
FIGURE 7

IMPACT OF DOOR LAYOUT: MEAN HOURLY THROUGHPUT PER FORKLIFT

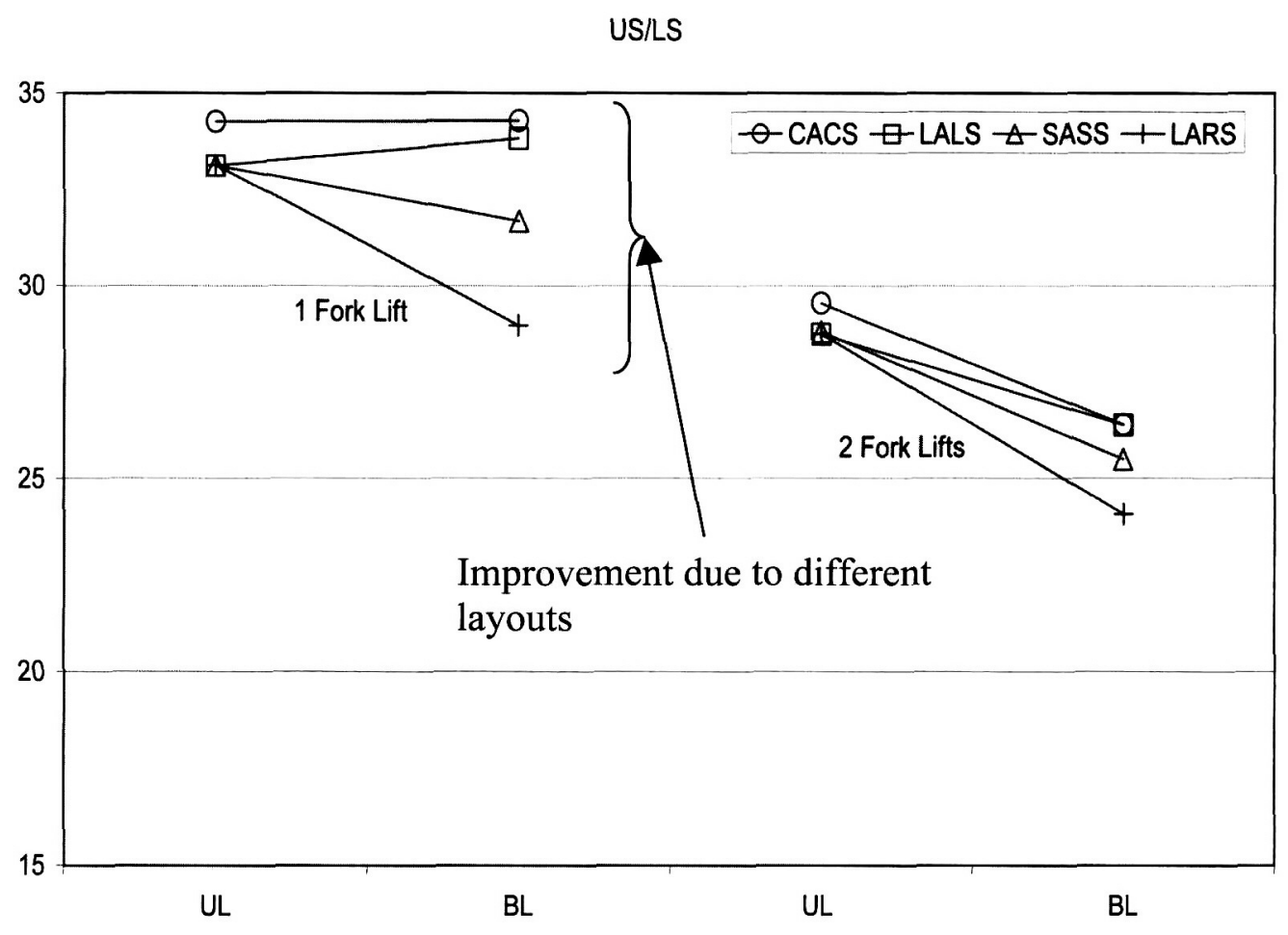

US/LT

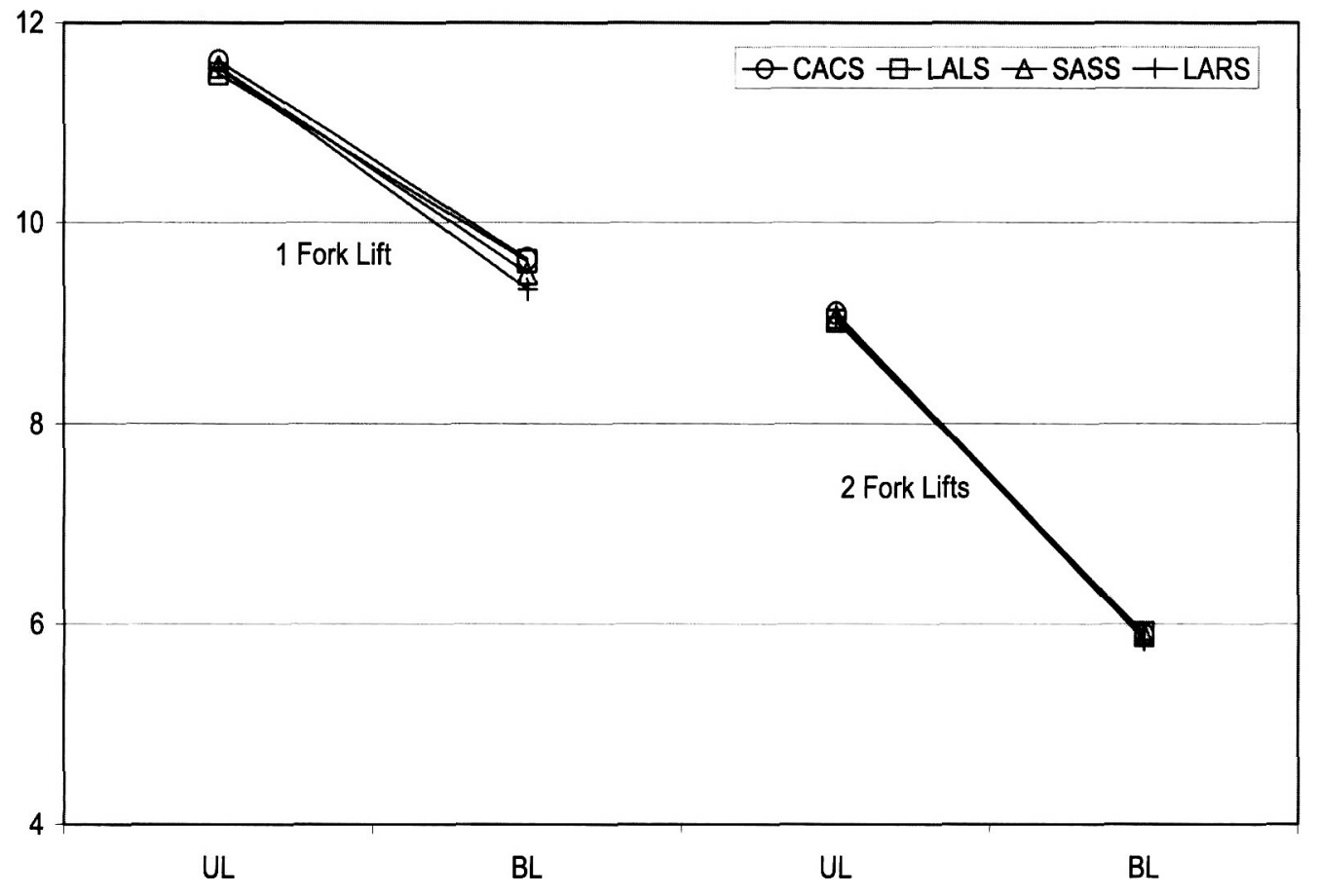


UT/LS
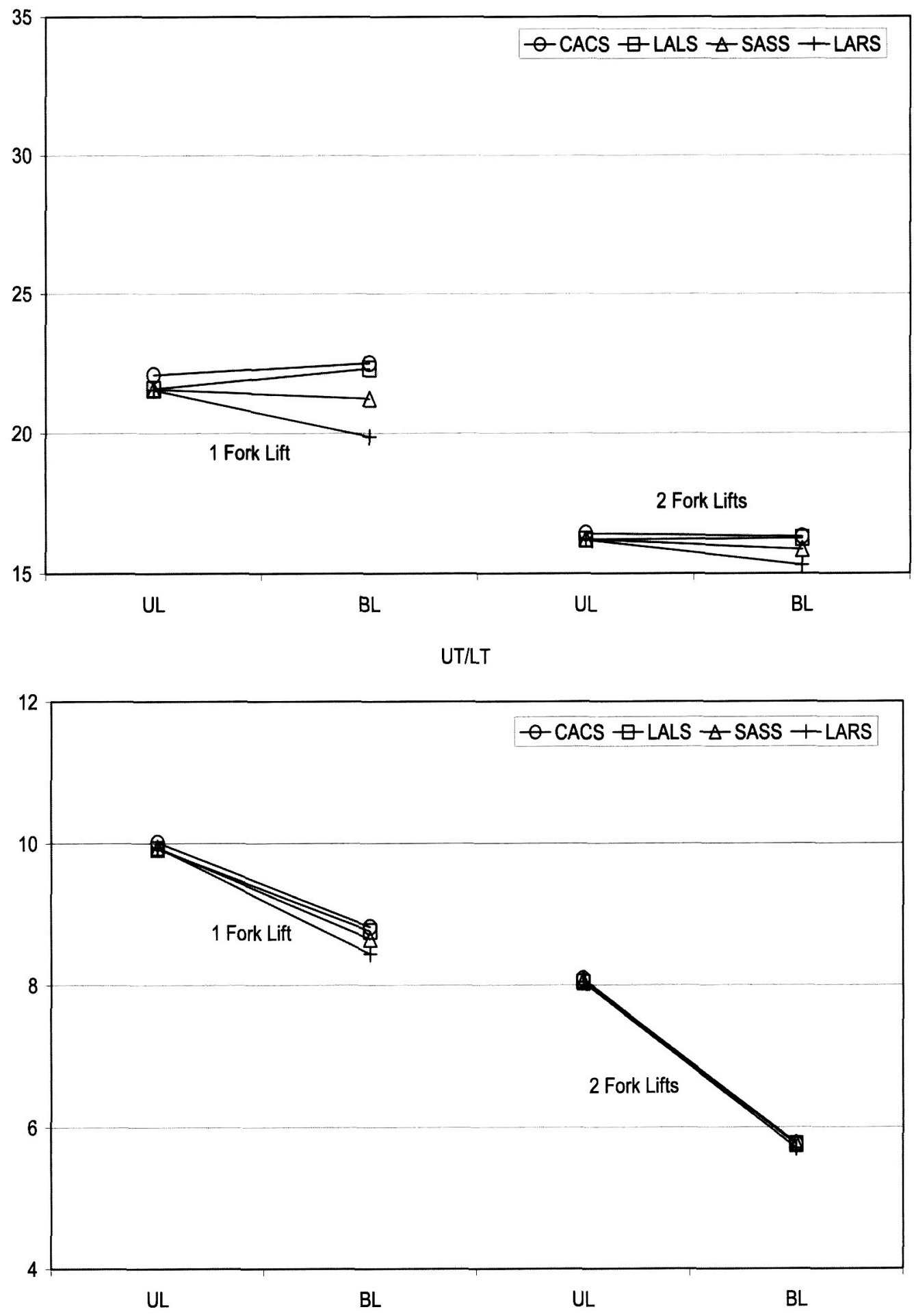
Figure 7 also shows that under uniform loads, the layout of a cross dock is less important. This is a useful result for managers and suggests that they can be less concerned over the layout if their shipping loads are uniform. Figure 7 shows that the layout CACS always produces the highest MTF. Specifically, the sub-plot US/LS shows that CACS produces the largest improvement (about five pallets per hour on average), when the freight mix is skewed and one forklift is assigned per receiving door. The distance traveled by the forklifts is reduced significantly when heavy flows in the skewed freight mix are assigned to the more central shipping doors, and as less congestion occurs at the doors when fewer forklifts and staging are used at both receiving and shipping doors. While it is appealing to minimize any localized congestion in the aisles by spreading the flow of forklifts as evenly as possible along the aisles, the layout SASS does not perform better than CACS. This observation suggests that travel time in a cross dock is attributed mainly to the actual distance traveled, rather than congestion in the aisles. It is the congestion at the doors that increases the travel time. Figure 7, indeed, shows that the improvement of a better layout is larger in cross docks that use fewer forklifts, unload pallets indirectly, or load pallet indirectly, since such cross docks are less congested at the doors. To realize the benefits of an improved layout in a cross dock, managers should thus monitor closely and manage the congestion at the doors, rather than the congestion along the aisles. A good layout will produce a higher MTF as long as the time saved from a shorter travel distance is not totally consumed as increased congestion at the doors.

It is seen that having two forklifts per receiving door, instead of one, is not advantageous from the perspective of throughput per forklift, because of the increased congestion at the doors. It also appears that the disadvantage of having more forklifts is true, regardless of whether staging is done at the doors. In fact, skewed load combined with multiple forklifts reduces MTF significantly, as seen from the increased negative slope of the lines in Figure 7 when moving from uniform to skewed loads for two forklifts per receiving door as compared to one forklift. Since MTF is defined as per forklift, having more forklifts does increase the overall throughput of a cross dock, even though the throughput per forklift is reduced. Managers must thus understand the effect of this decrease in throughput per forklift when adding forklifts to increase the throughput of a cross dock.

Figure 8 plots the MTF of opening different percentage of receiving doors in Experiment 2. Pair-wise comparison of the four subplots, again, shows that indirect unloading and indirect loading of pallets increase the MTF because of reduced congestion at the doors. While opening more receiving doors generally helps to reduce waiting at the receiving doors and increase the MTF, each subplot shows a smaller improvement in MTF in large cross docks. The subplots US/LS and US/LT, for example, show that opening all receiving doors (i.e., $100 \%$ open) in a large cross dock can even reduce the MTF, and produce the smallest MTF. This result is not surprising as forklifts in a large cross dock spend more time traveling between doors and less time waiting at the doors. Consequently, opening too many receiving doors in a large cross dock can significantly increase the travel distance and time between doors, with little or no further reduction of the short waiting time at the receiving doors. While managers may be tempted to use all the doors, as unused doors may be seen as a sign of lower productivity, this research shows that this policy may be of no value, and can even be counter-productive.

When heavy congestion exists at the shipping doors, opening more receiving doors is also less beneficial. The subplots US/LT and UT/LT in Figure 8, for example, show that opening more receiving doors produces little or small improvement in MTF when the outbound trailers are loaded directly with heavy congestion at the shipping doors. In contrast, when the outbound trailers are loaded indirectly, there is significantly less congestion at the shipping doors. The subplots US/LS (small cross dock) and UT/LS thus show that opening more receiving doors increases the throughput significantly as the forklifts can now unload pallets quickly with more receiving doors, and can also load pallets quickly (i.e., indirectly) at the shipping doors, producing a faster turnover of pallets at both doors. In summary, opening more receiving doors (to ease congestion at the receiving doors) increases the throughput significantly only when the congestion at the shipping doors is not excessive. This suggests that if the bottleneck is at the shipping doors, opening more receiving doors will not relieve the bottleneck. The congestion at the shipping doors must be improved before opening more receiving doors. 
FIGURE 8

IMPACT OF NUMBER OF OPEN RECEIVING DOORS: MEAN HOURLY THROUGHPUT PER FORKLIFT

US/LS
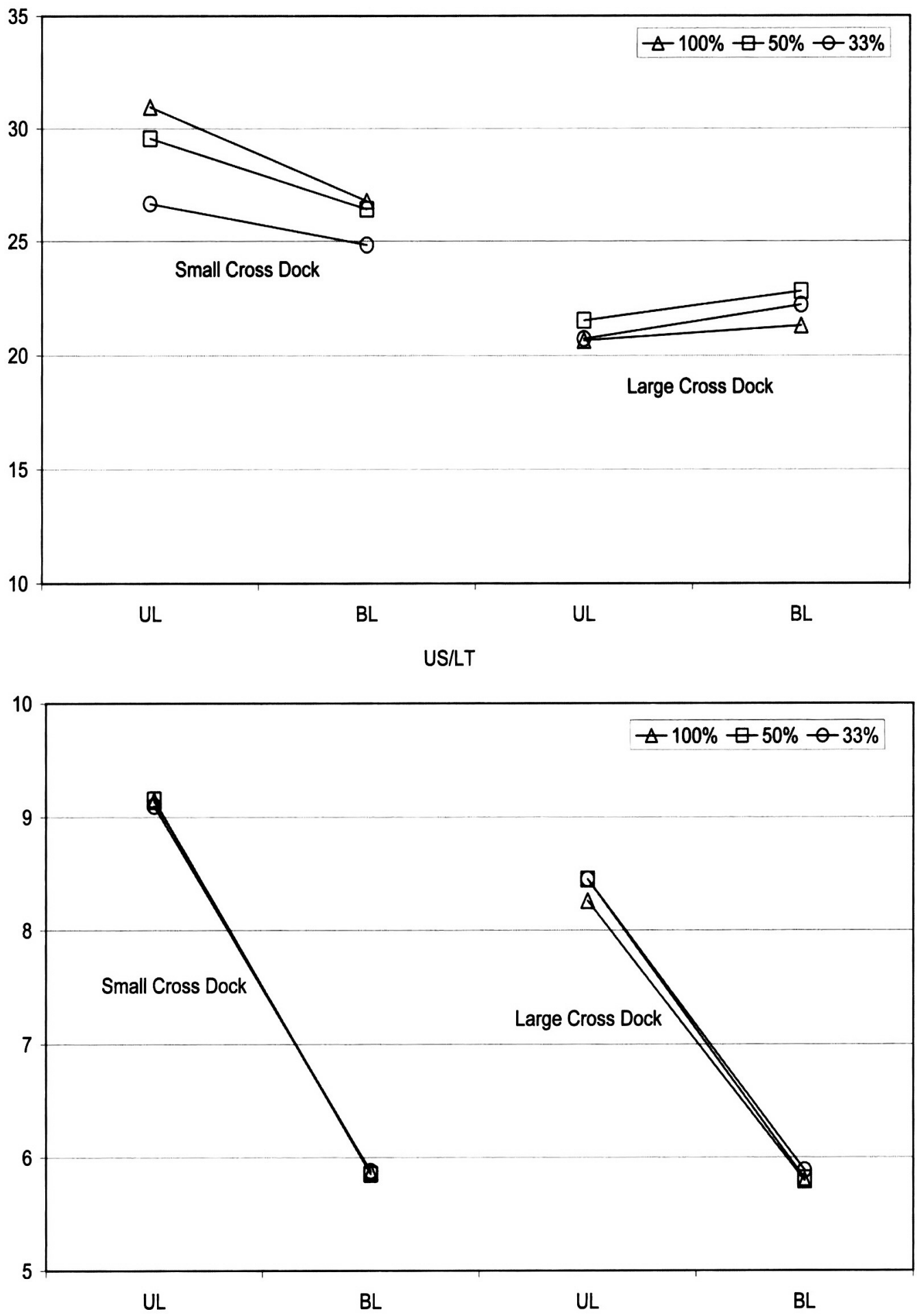
UT/LS
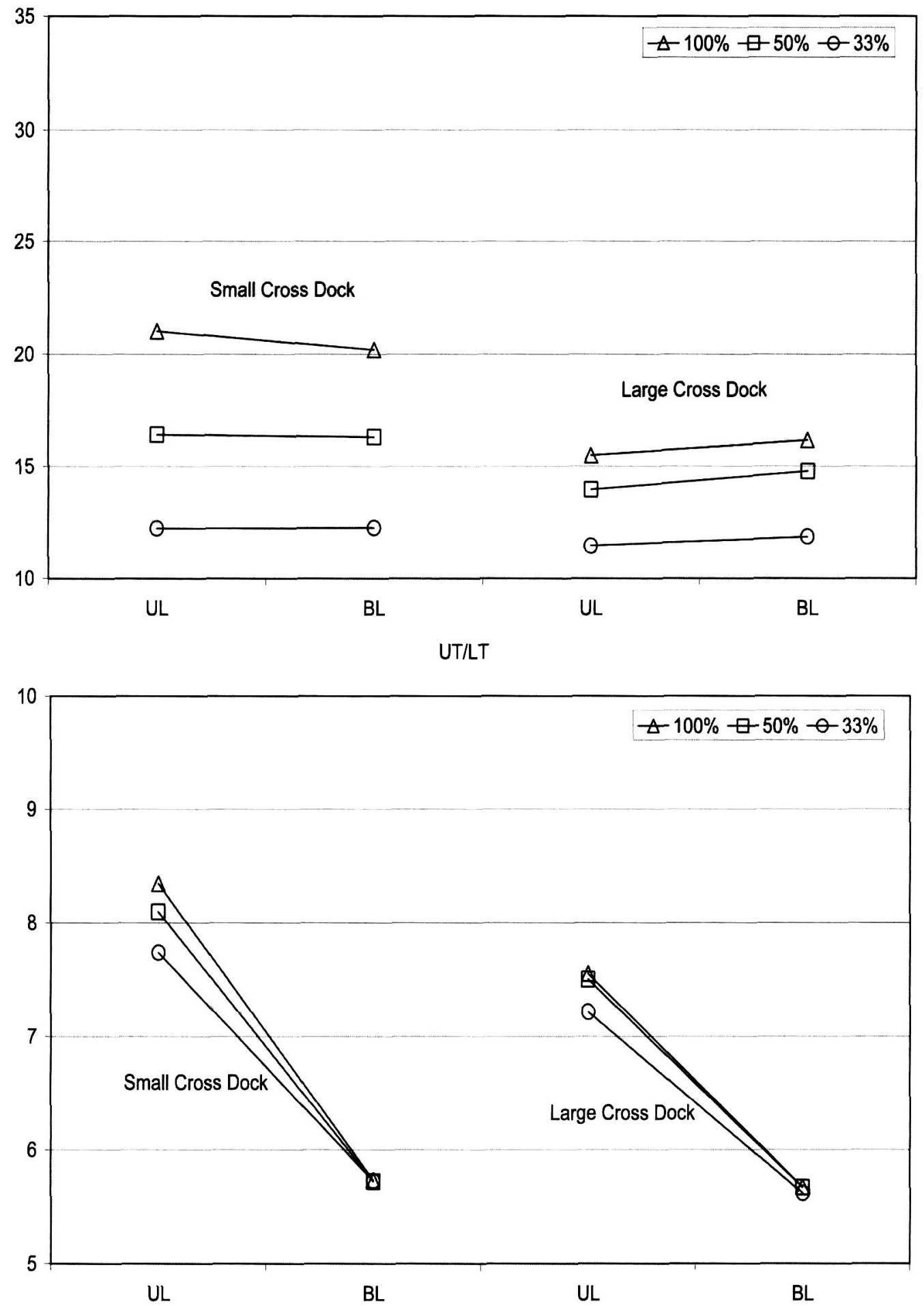
The subplots US/LT and UT/LT in both Figures 7 and 8 , show that a skewed freight mix hurts and reduces the throughput of a cross dock significantly when pallets are loaded directly, causing heavy congestion at shipping doors. However, if pallets are unloaded directly and loaded indirectly, the subplot UT/LS in both Figures 7 and 8 shows that the negative impact of a skewed freight mix is reduced significantly. Unloading pallets directly at the receiving doors reduces the rate at which forklifts visit the shipping doors, while loading the pallets indirectly at the shipping doors ensures that the same forklifts spend less time loading at the shipping doors-both effects help to mitigate the congestion at the shipping doors, even when the freight mix is heavily skewed. The negative effect of a skewed freight mix is also less pronounced in a large cross dock where forklifts spend more time traveling between doors, and produce less congestion at the doors (see subplots US/LS and UT/LS for large cross dock in Figure 8). In fact, under indirect loading and large cross docks (US/LS and UT/LS), the MTF even increases with a skewed load. This is due to the fact that an efficient layout (CACS) decreases travel time considerably for skewed loads (as compared to uniform loads) in larger cross docks, compared to that in smaller cross docks. Using a good layout, such as CACS, is thus more important in a large cross dock.

\section{Mean Handling Time per Pallet}

The Mean Handling Time per Pallet (MHP) measures the amount of labor minutes required to move one pallet from an inbound to an outbound trailer. Figure 9 shows the four sub-plots of MHP in Experiment 1, one for each pallet handling option. Each subplot shows that the layout CACS requires the smallest MHP, although the difference in MHP among the layouts is small. A larger MHP is also required when more forklifts are used, because of increased congestion in the cross dock. Consistent with the results on MTF, skewed loads decrease performance, i.e., MHP increases due to congestion at the shipping doors.

\section{FIGURE 9}

\section{IMPACT OF DOOR LAYOUT: MEAN HANDLING TIME PER PALLET}

US/LS

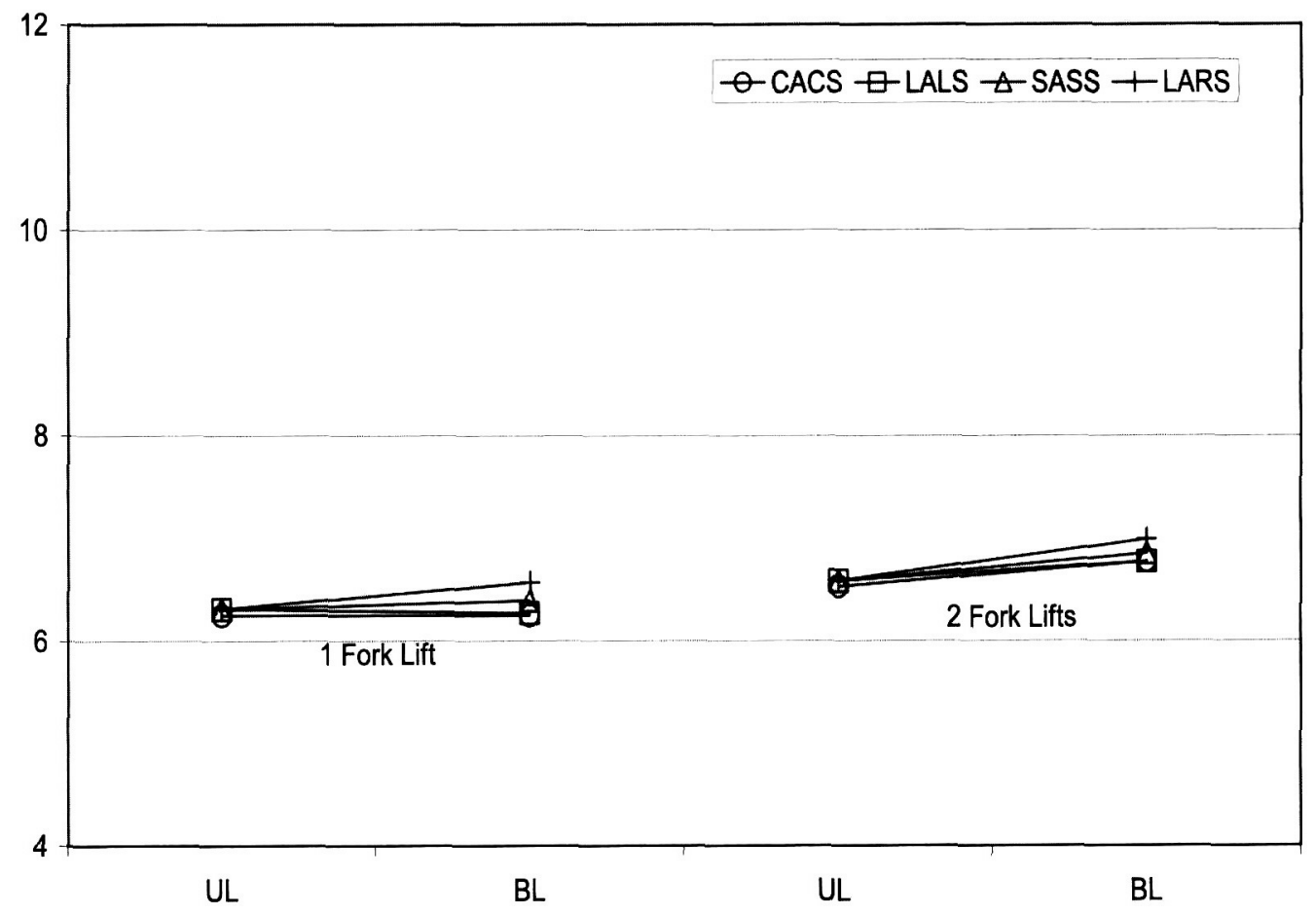


US/LT
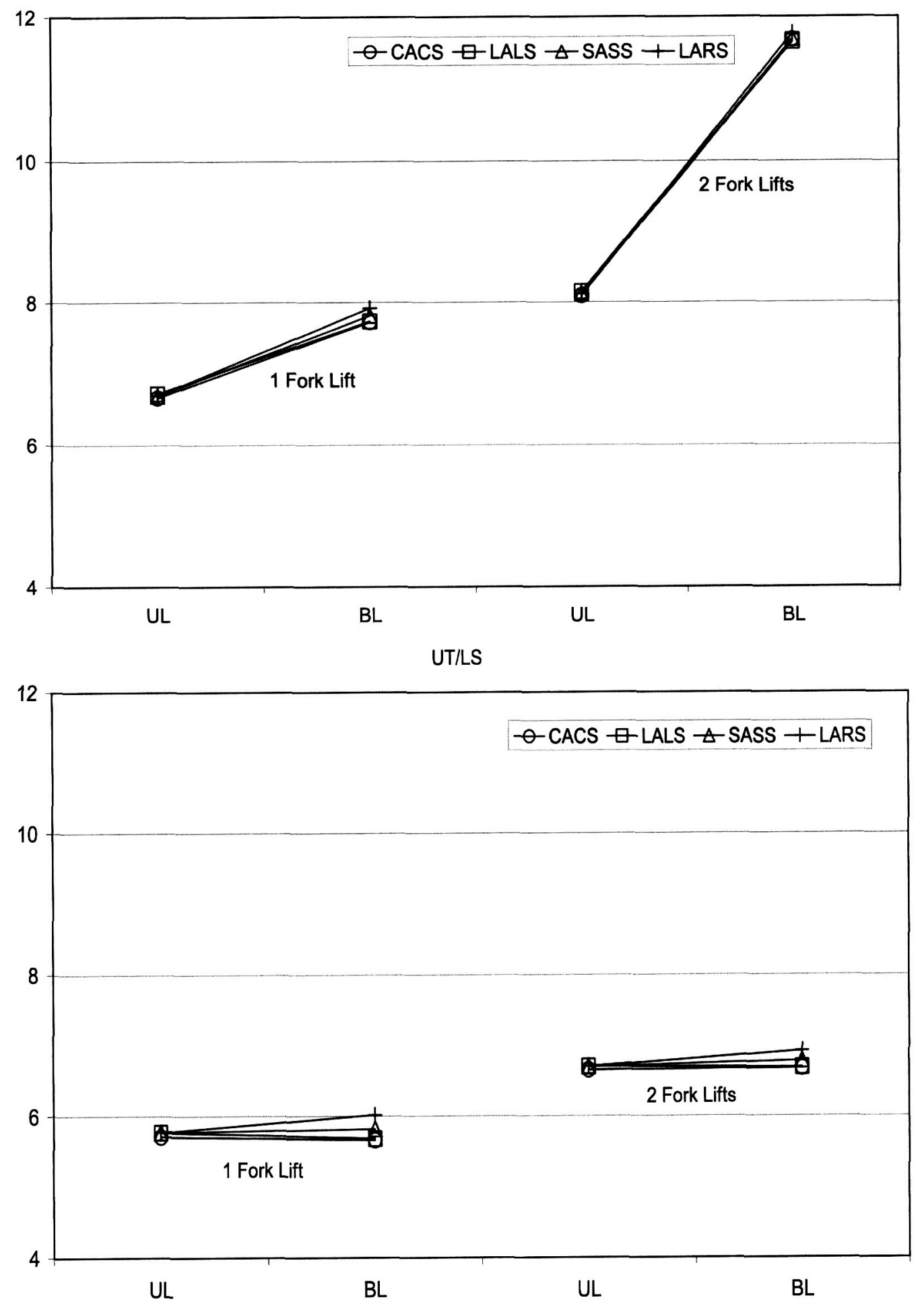
UT/LT

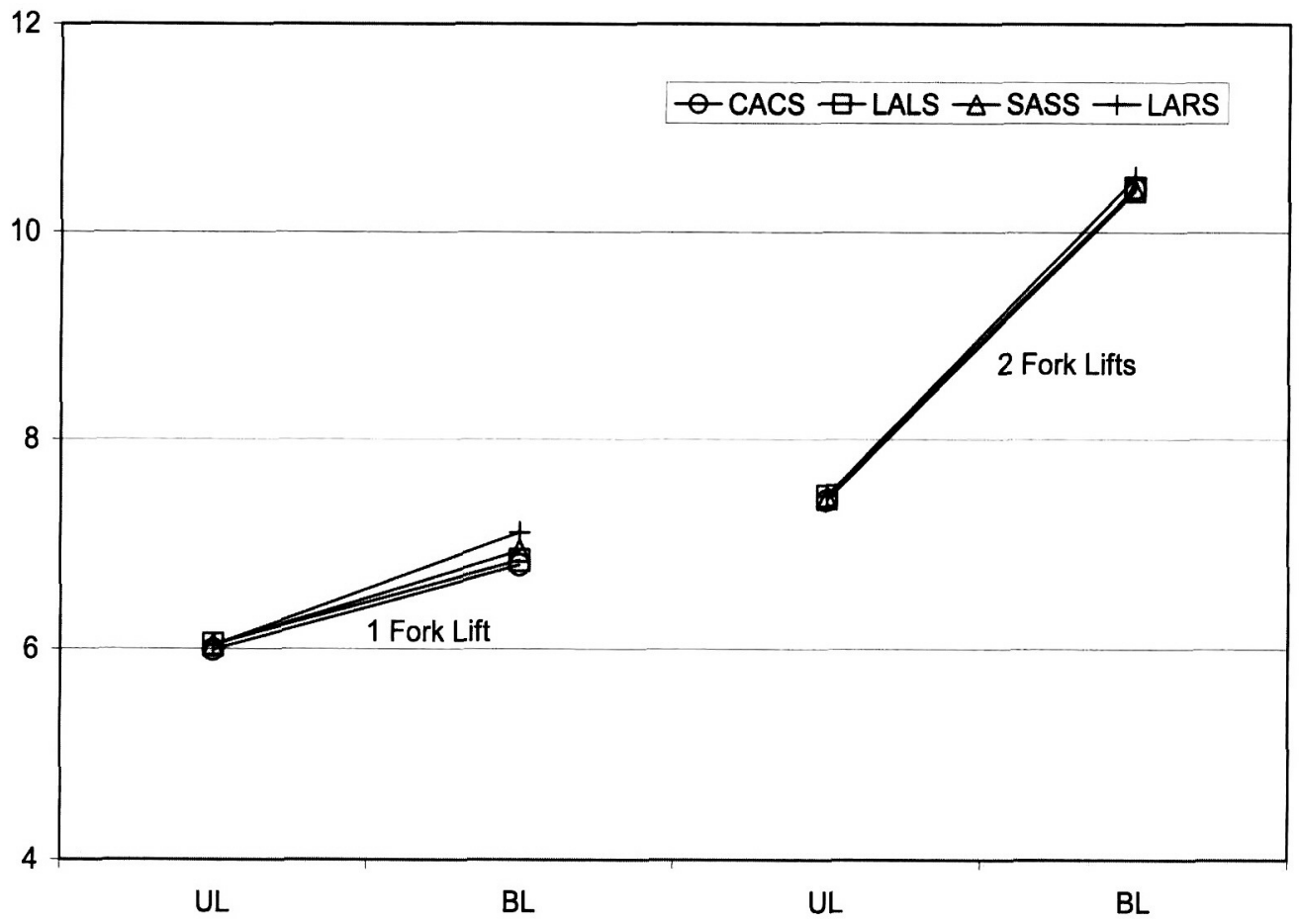

Figure 10 shows the MHP of opening different percentages of receiving doors in Experiment 2. The figure shows that the impact of opening more doors on MHP is small except for the subplot UT/LS. This subplot shows that opening fewer receiving doors increases MHP significantly, because of the significant congestion at the receiving doors caused by forklifts spending more time unloading directly at, and returning quickly to, the same receiving doors after loading pallets indirectly (i.e., quickly) at the shipping doors. When congestion occurs at the receiving doors rather than the shipping doors, opening more receiving doors reduces the congestion at the receiving doors (offsetting the increased travel distance), and is thus more beneficial. Managers should thus consider opening more receiving doors only if they see congestion at the receiving doors, and relatively less congestion at the shipping doors. Otherwise, there is no reason for opening more receiving doors.

The impact of unloading and loading pallets directly can also be seen in Figures 9 and 10. Comparing the subplots US/LS against UT/LS (and US/LT against UT/LT) in both Figures 9 and 10 shows that unloading pallets directly generally requires less MHP with one exception. The subplot UT/LS in Figure 10 shows that this occurs when $33 \%$ of the receiving doors are open (i.e., three forklifts are assigned to each open receiving door), such that the assigned forklifts spend a long time unloading directly at the receiving doors, but return quickly to the receiving doors after loading pallets indirectly (i.e. quickly) at the shipping doors-causing heavy congestion at the receiving doors. In this case, unloading directly requires a larger MHP. Thus, unloading pallets directly generally requires a smaller MHP, unless it causes heavy congestion at the receiving doors, because too few receiving doors are used. A heavy congestion at receiving doors is thus a signal for managers to open more receiving doors.

Comparing the subplots US/LS against US/LT (and UT/LS against UT/LT), in both Figures 9 and 10, shows that loading pallets directly requires a larger MHP. This result contradicts the advice of many experts to eliminate all double handling. Our result suggests that loading pallets directly causes excessive congestion at the shipping doors. To minimize MHP, it is thus better in most cross docks to load pallets indirectly. The negative consequences of congestion at shipping doors are made worse when direct loading (US/LT and UT/LT) is combined with skewed loads and multiple forklifts. The subplots US/LT and UT/LT in Figure 9 show that these three effects increase MHP significantly. 
FIGURE 10

IMPACT OF NUMBER OF OPEN RECEIVING DOORS: MEAN HANDLING TIME PER PALLET

US/LS
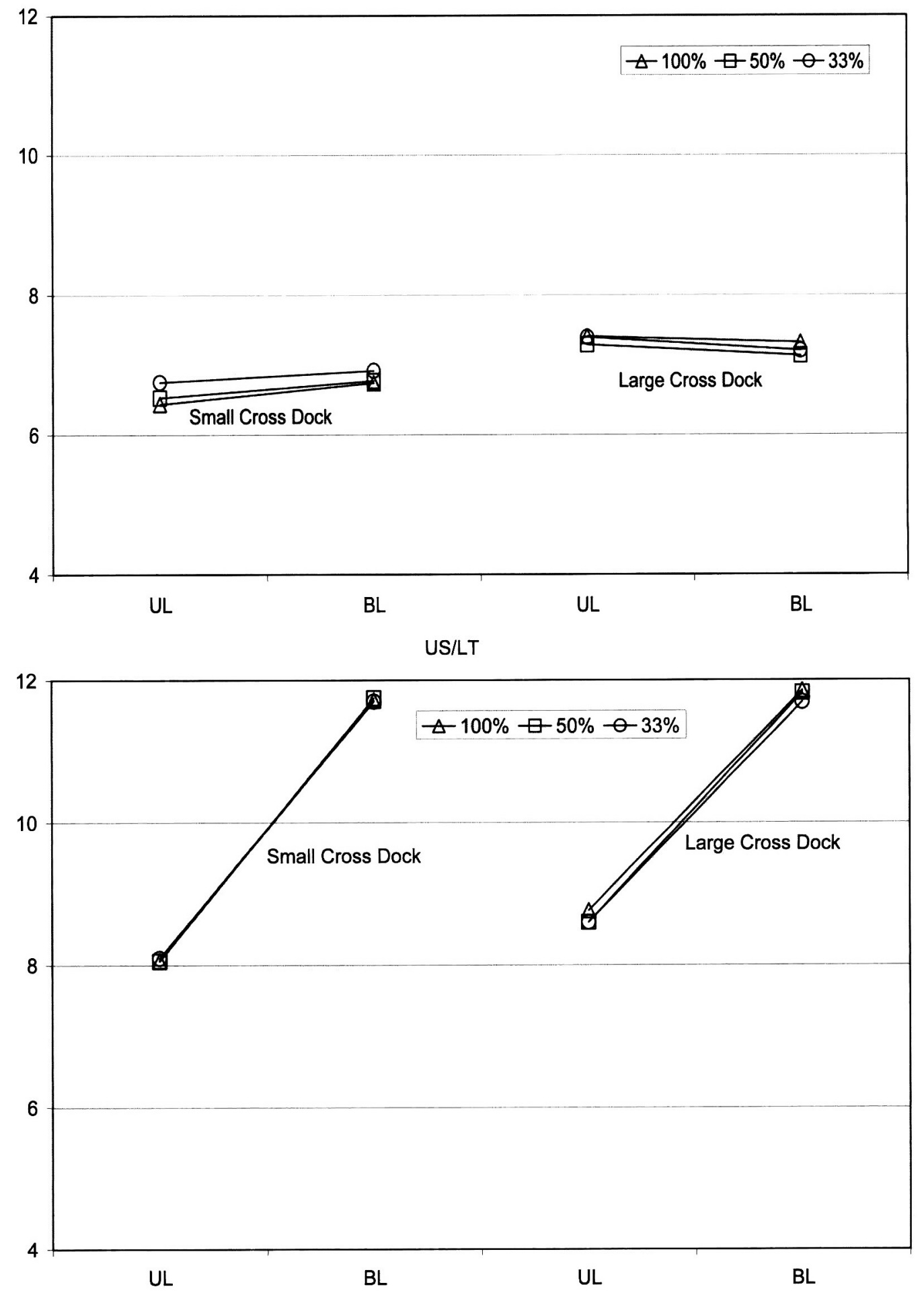
UT/LS
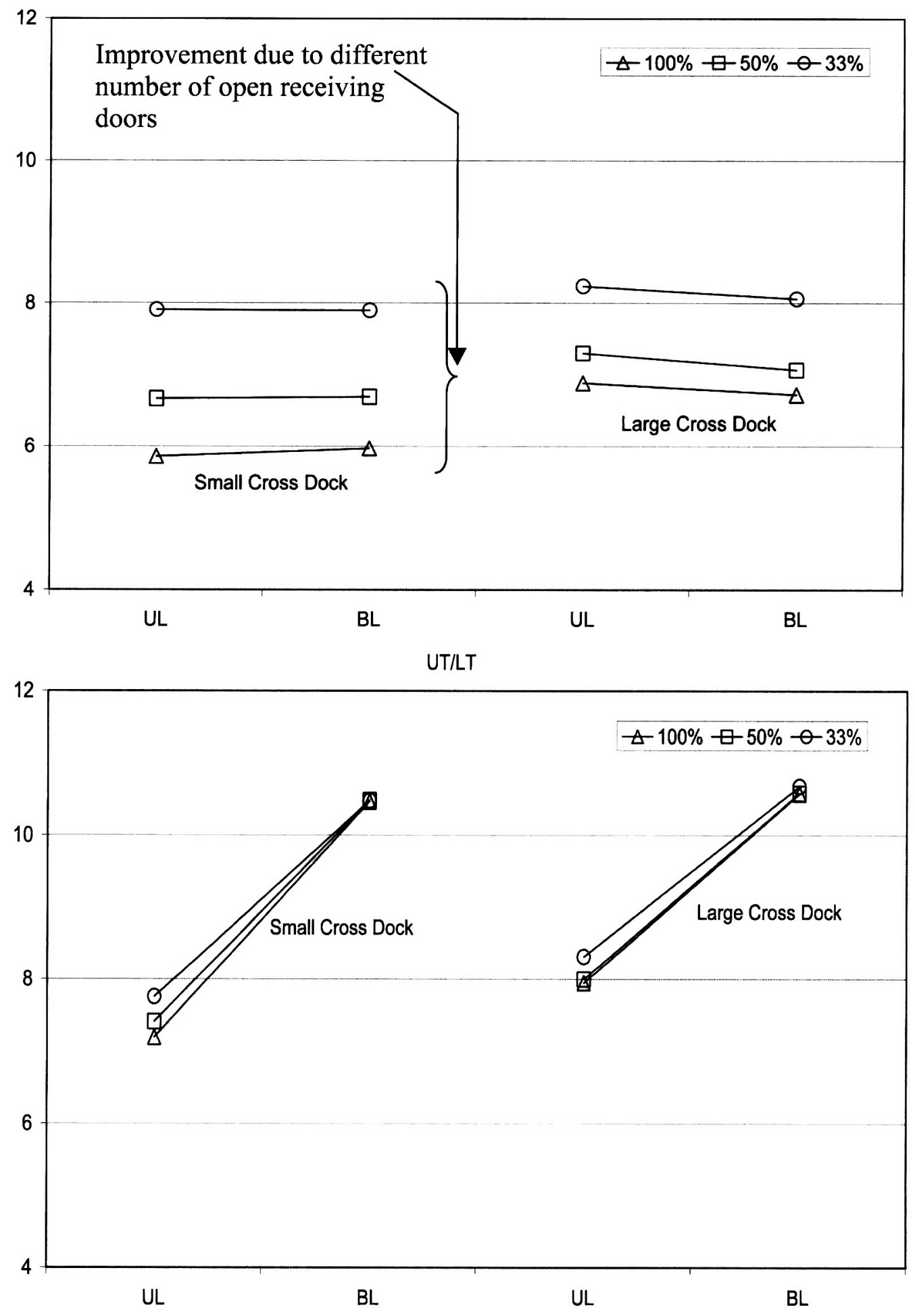

The results on MHP also provide an indication on the mean flow time required to move a pallet from an inbound to outbound trailer. For example, when pallets are unloaded and loaded directly between trailers, MHT is exactly equal to the mean flow time per pallet from inbound to outbound trailers. However, when staging is used, MHT provides a lower bound on the mean flow time per pallet. For example, if staging occurs at the receiving, shipping, or both doors, the mean flow time per pallet is a sum of the MHT and the mean waiting time per pallet that 
occurs at the receiving, shipping, or both staging areas respectively. The size of this mean waiting time per pallet is, in turn, dependent on how well the forklifts and the material handlers (responsible for unloading or loading the trailers) are coordinated to minimize the pallet waiting times in the staging areas. Since our results show that unloading pallets directly generally requires a smaller MHP, direct unloading of pallets will also generally produce a shorter mean flow time per pallet than staging pallets at the receiving doors. Similarly, our results show that loading pallets indirectly requires a smaller MHT. This suggests that indirect loading of pallets can also produce a shorter mean flow time per pallet than direct loading as long as the mean waiting time per pallet that occurs at the shipping staging areas is not excessive.

\section{CONCLUSIONS}

With cross docking becoming more common, it is important to analyze the operations of a cross dock to examine the decisions that affect its effectiveness. This article focuses primarily on the effects of staging inventory at receiving and/or shipping doors, as well as the effects of different layouts.

Our results show that unloading and loading pallets indirectly (i.e., US/LS), generally reduces the congestion at the receiving and shipping doors, and allows a cross dock to handle a higher throughput than the other three pallet handling options. Consistent with the experts' advice that indirect handling is a waste, our results show that unloading pallets directly (i.e., UT), does require less labor time and a shorter mean flow time per pallet. However, contrary to the same advice, our result shows that loading pallets indirectly (i.e., LS) requires less labor time to move pallets between inbound and outbound trailers. Loading pallets indirectly reduces the congestion at the shipping doors significantly and, in turn, requires less labor time to move pallets between the inbound and outbound trailers. Loading pallets indirectly also potentially helps to produce a shorter mean flow time, as long as the cross docking and staging functions are properly coordinated to minimize the pallet waiting time at the staging areas of shipping doors. Hence, to minimize the labor time and mean flow time required to move pallets between inbound and outbound trailers, unloading pallets directly and loading them indirectly (i.e., UT/LS) is the best. However, if the objective is to maximize the capacity of a cross dock to handle more pallets per unit time, indirect unloading and loading (i.e., US/LS) is the best, although it requires a higher labor time per pallet than UT/LS.

The layout CACS, which assigns inbound trailers and shipping destinations with heavier pallet flows to the more central doors, is the best. It not only maximizes the throughput, but also minimizes the labor time and mean flow time to move pallets between inbound and outbound trailers.

Obviously, opening too many receiving doors in a cross dock will increase the cost of security and inspection. To determine whether to open more receiving doors, one has to observe the congestion at the receiving and shipping doors. Opening more receiving doors is desirable only when congestion occurs at the receiving doors, while congestion at the shipping doors is not excessive. Opening more receiving doors when heavy congestion exists at the shipping doors will only feed more forklifts to the shipping doors, and worsen the congestion at the shipping doors, with little or no improvement in the number of pallets handled through the cross dock. Opening the right number of receiving doors is also more crucial in a large cross dock where the distance between doors is greater. Our result shows that opening too many receiving doors in a large cross dock can significantly hurt its throughput.

In general, it is seen that skewed loads decrease performance, since it increases congestion, especially at the shipping doors. However, in large cross docks and cross docks using small numbers of forklifts, the decreased travel time due to skewed loads can offset the additional congestion and improve performance. In addition the use of multiple forklifts always decreases the productivity per forklift due to congestion. These two effects combined with the effect of direct unloading and loading make the performance significantly worse. Our experiments thus show that congestion at the doors has a strong effect on the performance of a cross dock. Consequently, from a managerial perspective, it is important to consider the size of the cross dock, staging of inventory, number of forklifts, number of open receiving doors, and door layout, when designing a cross dock to minimize the congestion at the doors, particularly the shipping doors. 


\section{NOTES}

Allegri, Theodore H. (1993), Managing Warehouse and Distribution Operations, Englewood Cliffs, NJ: Prentice Hall.

Banks, Jerry, John S. Carson, Barry L. Nelson, and David M. Nicol (2004), Discrete-Event System Simulation, $4^{\text {th }}$ ed., Englewood Cliffs, NJ: Prentice Hall International Series in Industrial and Systems Engineering.

Bartholdi, J. J. III and Kevin R. Gue (2004), “The Best Shape for a Cross Dock,” Transportation Science, Vol. 38, No. 2, pp. 235-244.

Bartholdi, J. J. III and Kevin R. Gue (2000), "Reducing Labor Costs in an LTL Cross Docking Terminal," Operations Research, Vol. 48, No. 6, pp. 823-832.

Bartholdi, J. J. III, Kevin R. Gue, and Keebom Kang (2001), "Staging Freight in a Cross Dock," Proceedings of the International Conference on Industrial Engineering and Production Management, (May), Quebec City, Canada, 10 pages.

Federgruen, Awi (1993), "Centralized Planning Models for Multi-echelon Inventory Systems under Uncertainty," in: Graves, Sean C., Alexander H. G. Rinnooy Kan, and Paul H. Zipkin (eds.), Logistics of Production and Inventory, Elsevier North-Holland, Amsterdam, Vol. 4, pp. 133-174.

Federgruen, Awi, Gregory Prastacos, and Paul H. Zipkin (1986), "An Allocation and Distribution Model for Perishable Products," Operations Research, Vol. 34, No. 1, pp. 75-82.

Federgruen, Awi and Paul H. Zipkin (1984), "A Combined Vehicle Routing and Inventory Allocation Problem," Operations Research, Vol. 32, No. 5, pp. 1019-1037.

Galbreth, Michael R., James A. Hill, and Sean Handley (2008), "An Investigation of the Value of Cross Docking for Supply Chain Management," Journal of Business Logistics, Vol. 29, No. 1, pp. 225-239.

Gue, Kevin R. (1999), "The Effects of Trailer Scheduling on the Layout of Freight Terminals," Transportation Science, Vol. 33, No. 4, pp. 419-428.

Gue, Kevin R. (2007), "Warehouse without Inventory," International Commerce Review, Vol. 7, No. 2, pp. 124-132.

Gue, Kevin R. and Keebom Kang (2001), "Staging Queues in Material Handling and Transportation Systems," Proceedings of the 2001 Winter Simulation Conference, (December), Arlington, VA, pp. 1104-1108.

Gümus, Mehmet and James H. Bookbinder (2004), "Cross-docking and its Implications in Location-distribution Systems," Journal of Business Logistics, Vol. 25, No. 2, pp. 199-228.

Huq, Faizul, Kenneth Cutright, Vernon Jones, and Douglas A. Hensler (2006), "Simulation Study of a Two-level Warehouse Inventory Replenishment System," International Journal of Physical Distribution and Logistics Management, Vol. 36, No. 1, pp. 51-65.

Jönsson, Henrik and Edward A. Silver (1987), "Stock Allocation Among a Central Warehouse and Identical Regional Warehouses in a Particular Push Inventory Control System," International Journal of Production Research, Vol. 25, No. 2, pp. 191-205.

Kelton, David W., Randall P. Sadowski, and David T. Sturrock (2004), Simulation with Arena, 4th ed., New York: McGraw-Hill.

Kinnear, Ewen (1997), "Is there any Magic in Cross Docking?" Supply Chain Management, Vol. 2, No. 2, pp. 49-52. 
Masters, James M. (1993), "Determination of Near Optimal Stock Levels for Multi-echelon Distribution Inventories," Journal of Business Logistics, Vol. 14, No. 2, pp. 165-195.

Mulcahy, David E. (1994), Warehouse Distribution \& Operations Handbook, New York: McGraw-Hill.

Napolitano, Maida (2000), Making the Move to Cross docking, Oak Brook, IL: Warehousing Education and Research Council.

Nozick, Linda K. and Mark A. Turnquist (1998), "Integrating Inventory Impacts into a Fixed-Charge Model for Locating Distribution Centers," Transportation Research. Part E, Logistics \& Transportation Review, Vol. 34, No. 3, pp. 173-186.

Snyder, Glenn (1995), “Toughened by Wal-Mart," Progressive Grocer, Vol. 74, No. 2, pp. 89-93.

Sung, Chang Sup and Sang Hwa Song (2003), "Integrated Service Network Design for a Cross-docking Supply Chain Network," Journal of Operational Research Society, Vol. 54, No. 12, pp. 1283-1295.

Tompkins, James A., John A. White, Yavuz A. Bozer, and J. M. A. Tanchoco (2003), Facilities Planning, $3^{\text {rd }}$ ed., New York: John Wiley \& Sons.

Tsui, Louis Y. and Chia-Hao Chang (1990), "A Microcomputer Based Decision Support Tool for Assigning Dock Doors in Freight Yards," Computer and Industrial Engineering, Vol. 19, No. 1-4, pp. 309-312.

Tsui, Louis Y. and Chia-Hao Chang (1992), “An Optimal Solution to Dock Doors Assignment Problem," Computer and Industrial Engineering, Vol. 23, No. 1-4, pp. 283-286.

Waller, Matthew A., C. Richard Cassady, and John Ozment (2006), "Impact of Cross-docking on Inventory in a Decentralized Retail Supply Chain," Transportation Research. Part E, Logistics \& Transportation Review, Vol. 42, No. 5, pp. 359-382.

Wang, Joama-Fu and Amelia Regan (2008), "Real-time Trailer Scheduling for Cross Dock Operations," Transportation Journal, Vol. 47, No. 2, pp. 5-20.

Williams, Brent D. and Travis Tokar (2008), "A Review of Inventory Management Research in Major Logistics Journals: Themes and Further Directions," The International Journal of Logistics Management, Vol. 19, No. 2, pp. 212-232. 


\section{ABOUT THE AUTHORS}

Kum Khiong Yang (Ph.D. Indiana University) is a professor of Operations Management at the Singapore Management University. He has a bachelor degree in Mechanical Engineering from the National University of Singapore and an MBA and a Ph.D. in Operations Management from the Kelly School of Business, Indiana University. He is also a SAP Certified R/3 application consultant and has published extensively in many reputable journals.

Jaydeep Balakrishnan (Ph.D. Indiana University) completed his doctorate in Operations Management from Indiana University. Prior to this he obtained an MBA at the University of Georgia, and an undergraduate degree in Mechanical Engineering from the Visvesvaraya National Institute of Technology, Nagpur University, India. His research interests include facility layout and supply chain management. Jaydeep has presented papers at various international conferences and has published over 30 articles in reputable journals.

Chun Hung Cheng (Ph.D. University of Iowa) received his BSSc from the Chinese University of Hong Kong and MSc in Computer Science, MBA, and Ph.D. from the University of lowa. He is an associate professor at the Department of Systems Engineering \& Engineering Management, the Chinese University of Hong Kong (CUHK). $\mathrm{He}$ is interested in the use of information technology in logistics and operations management. His work has produced over 60 journal publications.

Contact author: Kum Khiong Yang; E-mail: kkyang@smu.edu.sg 
Using simulation, we examine the decisions in moving freight between inbound and outbound trailers in a cross dock. The decisions examined include direct versus indirect handling of pallets, number of open receiving doors, door layout, number of forklifts, size of cross dock and freight mix. This study provides useful insights on handling freight in a cross dock.

Key Words: Computer simulation; Cross dock; Logistics; Material handling

\author{
"The Impact of Point-of-sale Data Inaccuracy and Inventory Record Data Errors" \\ Heather Nachtmann, Matthew A. Waller, and David W. Rieske
}

The presence or absence of error in point-of-sale (POS) data and inventory system records directly affects retailer performance. This study identifies various error sources in retail supply chains and studies the influence of inventory and POS (demand) errors in a simulated retail outlet according to fill rate and average inventory. Other things being equal, we find that inventory record error reduces fill rate more than demand error. This study adds further evidence to other studies that suggest the costs caused by errors in POS systems may be overstated.

Key Words: Fill rates; Inventory levels; Inventory system accuracy; Retail

\title{
"User Influence on the Relationship between Forecast Accuracy, Application and Logistics Performance" Carlo D. Smith and John T. Mentzer
}

When companies develop and apply more accurate forecasts in their planning and management activities, they have the potential to improve performance throughout their organization and across the supply chain. To realize these improvements, however, companies must (1) implement techniques and practices that improve forecast accuracy, and (2) integrate the more accurate forecasts into their planning and management activities. While much research has focused on accomplishing the first of these requirements, few studies have investigated the important role that user's play in the application of forecasts for logistics planning and management. This article establishes a connection between forecast performance, user perceptions of the quality of forecasts they receive, the extent that they use the forecasts and the resulting impact on logistics performance.

Key Words: Forecast accuracy; Forecasting management; Forecast utilization; Logistics performance 